\title{
Upscaling the Surveillance of Tick-borne Pathogens in the French Caribbean Islands
}

\author{
Mathilde Gondard 1,2, Sabine Delannoy ${ }^{3}$, Valérie Pinarello ${ }^{2,4}$, Rosalie Aprelon 2,4, \\ Elodie Devillers 1, Clémence Galon 1, Jennifer Pradel 2,4, Muriel Vayssier-Taussat 1, \\ Emmanuel Albina ${ }^{2,4}$ and Sara Moutailler 1,* \\ 1 UMR BIPAR, Animal Health Laboratory, ANSES, INRAE, National Veterinary School of Alfort, \\ Paris-Est University, Maisons-Alfort, 94700 Paris, France; mathilde.gondard@gmail.com (M.G.); \\ elodie.devillers@anses.fr (E.D.); clemence.galon@anses.fr (C.G.); Muriel.taussat@inrae.fr (M.V.-T.) \\ 2 CIRAD, UMR ASTRE, F-97170 Petit-Bourg, 97170 Guadeloupe, France; valerie.pinarello@cirad.fr (V.P.); \\ rosalie.aprelon@cirad.fr (R.A.); jennifer.pradel@cirad.fr (J.P.); emmanuel.albina@cirad.fr (E.A.) \\ 3 IdentyPath Platform, Laboratory for Food Safety, ANSES, Maisons-Alfort, 94700 Paris, France; \\ sabine.delannoy@anses.fr \\ 4 ASTRE, Univ Montpellier, CIRAD, INRAE, 34000 Montpellier, France \\ * Correspondence: sara.moutailler@anses.fr; Tel.: +33-1-49-77-46-50
}

Received: 6 February 2020; Accepted: 28 February 2020; Published: 1 March 2020

\begin{abstract}
Despite the high burden of vector-borne disease in (sub)tropical areas, few information are available regarding the diversity of tick and tick-borne pathogens circulating in the Caribbean. Management and control of vector-borne disease require actual epidemiological data to better assess and anticipate the risk of (re)emergence of tick-borne diseases in the region. To simplify and reduce the costs of such large-scale surveys, we implemented a high-throughput microfluidic real-time PCR system suitable for the screening of the main bacterial and parasitic genera involved in tickborne disease and potentially circulating in the area. We used the new screening tool to perform an exploratory epidemiological study on 132 adult specimens of Amblyomma variegatum and 446 of Rhipicephalus microplus collected in Guadeloupe and Martinique. Not only the system was able to detect the main pathogens of the area-Ehrlichia ruminantium, Rickettsia africae, Anaplasma marginale, Babesia bigemina and Babesia bovis - but the system also provided evidence of unsuspected microorganisms in Caribbean ticks, belonging to the Anaplasma, Ehrlichia, Borrelia and Leishmania genera. Our study demonstrated how high-throughput microfluidic real-time PCR technology can assist large-scale epidemiological studies, providing a rapid overview of tick-borne pathogen and microorganism diversity, and opening up new research perspectives for the epidemiology of tickborne pathogens.
\end{abstract}

Keywords: tick; bacteria; parasites; Caribbean; microfluidic real-time PCR

\section{Introduction}

Among hematophagous arthropods, ticks transmit the greatest variety of pathogens of public health and veterinary importance whose incidence is growing worldwide [1]. The French West Indies, including the islands of Guadeloupe and Martinique, are located in the heart of the Caribbean Neotropical zone, a cosmopolitan area characterized by a tropical climate, intercontinental trade and animal movements (legal and illegal trade as well as bird migration) that are favorable for the introduction and spread of ticks and tick-borne pathogens (TBPs) [2]. Yet, the epidemiological situation of the Caribbean area with regard to the diversity of tick species and tick-borne diseases (TBDs) is poorly documented [3]. 
Amblyomma variegatum, Rhipicephalus microplus and Rhipicephalis sanguineus sensu lato are the main tick species found in the French Antilles that are involved in the transmission of TBPs of medical and veterinary importance [3]. While Rhipicephalis sanguineus sensu lato are mainly found infesting dogs, Amblyomma variegatum, also known as the tropical bont tick (TBT) in the Caribbean, and Rhipicephalus microplus (the "cattle tick") have been the two main tropical livestock pests since their introduction in the Caribbean through imports of infested animals from Africa and Asia in the 18th19th centuries [3-9].

R. microplus, a one-host tick highly specific to cattle, is mainly involved in the transmission of Anaplasma marginale, Babesia bovis and Babesia bigemina, causing bovine anaplasmosis and babesiosis, respectively. These endemic pathogens are responsible for important economic loss to farming industries in the Caribbean and are still a sanitary threat $[7,10]$.

A. variegatum is a three-host tick species, with immature stages that can parasitize a wide range of hosts, including rodents, mongooses and birds, as well as an adult stage that is more specific to cattle [11]. This tick species is mainly involved in Ehrlichia ruminantium transmission, the causative agent of heartwater, a fatal ruminant ehrlichiosis. Although A. variegatum is present in both Martinique (mainly in the south) and Guadeloupe (widespread), E. ruminantium has only been reported in Guadeloupe [12]. In addition, A. variegatum ticks are also a vector of Rickettsia africae, which is common in the Caribbean and can induce human rickettsiosis, called African tick-bite fever $[9,13,14]$. African tick-bite fever remains a concern mainly for travelers. Indeed, despite high levels of tick infection and seroprevalence in human and cattle sera, only two human cases of African tick-bite fever have been reported to date, only in travelers returning from Guadeloupe [9,15]. Lastly, $A$. variegatum is also involved in the epidemiology of Theileria mutans and Theileria velifera, two cattle parasites with low and no virulence, respectively $[6,8]$. However, very few information is available on the distribution and prevalence of these two Apicomplexa in the Caribbean.

Most of the epidemiological data available did not survey or determine the diversity of TBPs circulating in the Caribbean, since they were often limited to the detection of some well-known pathogens, via serological studies in animals or humans, or on molecular biology testing (PCR, nested PCR) [16,17]. Thus, regarding the lack of recent information and the limited extent of the epidemiological data available, new insight into the epidemiology of ticks and TBPs was needed to better address the prevalence and (re)emergence of TBDs in the Caribbean.

In order to improve the surveillance ability of tick-borne pathogens in the Neotropical area, we implemented a new large-scale screening tool based on a microfluidic real-time PCR approach. Microfluidic real-time PCR is based on the use of microfluidic chips allowing the performance of up to 9216 individual PCR reactions per run, and thus the simultaneous detection of up to 96 targets in up to 96 samples. The recent development and use of a microfluidic real-time PCR for the rapid and concomitant detection of a large panel of TBPs in European ticks has paved the way for promising and broader surveillance capacities [18-22]. Here, we adapted and designed a new microfluidic realtime PCR system suited to the simultaneous screening of the main bacteria and protozoans potentially transmitted by ticks in the Caribbean. Not only did the system enable the direct detection of 49 bacterial and parasitic species, but it also enabled, within a single experiment, broader capacities for the surveillance of potentially pathogenic microorganisms by targeting the main bacterial and protozoan genera involved in human and animal vector-borne diseases (one protozoan phylum and eight bacterial and protozoan genera). In addition, the system enabled the molecular identification of the three well-known tick species involved in TBDs in the Caribbean in order to confirm the morphological tick species identification determined on the field. Finally, we used the new highthroughput detection tool to conduct large-scale screening of TBPs in 132 A. variegatum and 446 R. microplus adult specimens collected in Guadeloupe and Martinique. We demonstrated the system's ability to detect well-known TBPs occurring in the French West Indies, as well as unsuspected TBPs and potential new microorganisms. This new method can considerably improve the ability to monitor emerging and non-emerging TBPs through large-scale surveys in the Caribbean area. 


\section{Results}

\subsection{Implementation of the High-throughput Microfluidic Real-time PCR System for Tick-borne Pathogen Screening}

The high-throughput microfluidic real-time PCR system developed for the screening of known and potential TBPs in Caribbean ticks included 61 sets of primers and probes. Among them, 49 designs were developed for the detection of bacterial $(n=32)$ and protozoan $(n=17)$ species and bacterial $(n=5)$ and protozoan $(n=3)$ genera/phyla (Table 1$)$. Three sets of primers and probes were developed for the molecular identification of the three tick species found in the Caribbean: $A$. variegatum, $R$. microplus and $R$. sanguineus sensu lato (Table 1). Lastly, we developed a design targeting a conserved region of the $16 \mathrm{~S}$ rRNA genes in ticks, called "Tick spp.", used as a control for DNA/RNA extraction (Table 1).

Table 1. List of primer/probe sets constituting the BioMark system, with the positive controls used for their validation (new designs mainly). *: Design from Michelet et al., 2014 [18]. **: include all the controls belonging to the genus described in the table and targeted by specific design. Plasmids used as control are recombinant PBluescript IISK+ containing the target gene.

\begin{tabular}{|c|c|c|c|c|c|}
\hline Microorganisms & Target & Designname & Sequence(5' à3') & Length (bp) & Controls \\
\hline \multirow{3}{*}{ Rickettsia spp. } & \multirow{3}{*}{ gltA } & Rick_spp_gttA_F & GTCGCAAATGTTCACGGTACIT & \multirow{3}{*}{78} & \multirow{3}{*}{${ }^{*}$, Culture of R. sloonaca } \\
\hline & & Rick_spp_gltA_R & TCTTCGTGCATTTCITTCCATTG & & \\
\hline & & Rick_spp_gitA_P & TGCAATAGCAAGAACCGTAGGCTGGATG & & \\
\hline \multirow{3}{*}{ Rickettsiamassiliae* } & \multirow{3}{*}{ ITS } & Ri_ma_IIS_F & GTTATTGCATCACTAATGTTATACTG & \multirow{3}{*}{128} & \multirow{3}{*}{ Culture } \\
\hline & & Ri_ma_IIS_R & GTTAATGTTGTTGCACGACTCAA & & \\
\hline & & Ri_ma_IIS_P & TAGCCCCGCCACGATATCTAGCAAAAA & & \\
\hline \multirow{3}{*}{ Rickettsia rickettsii* } & \multirow{3}{*}{ ITS } & Ri_i__ISSF & TCTACTCACAAAGTTATCAGGTTAA & \multirow{3}{*}{124} & \multirow{3}{*}{ Plasmid } \\
\hline & & Ri_in_IIS_R & CCTACGATACTCAGCAAAATAATTT & & \\
\hline & & Ri_i__ITS_P & TCGCTGGATATCGTTGCAGGACTACAG & & \\
\hline \multirow{3}{*}{ Rickettsia conorii } & \multirow{3}{*}{ scal } & Ri_co_scal_F & GTAGATGCTTCATAGAATACTGC & \multirow{3}{*}{88} & \multirow{3}{*}{$\begin{array}{c}\text { Infected Rhipicephalus } \\
\text { sanouineussl. }\end{array}$} \\
\hline & & Ri_co_scal_R & CCAAATTTAGTCTACCTTGTGATC & & \\
\hline & & Ri_co_sca1_P & TCCTCCTGACGTATTAAAAGAAGCTGAAGCT & & \\
\hline \multirow{3}{*}{ Rickettsia africae } & \multirow{3}{*}{ scal } & Ri_af_scal_F & GATACGACAAGTACCTCGCAG & \multirow{3}{*}{122} & \multirow{3}{*}{ Culture } \\
\hline & & Ri_af_scal_R & GGATTATATACTTTAGGITCGTTAG & & \\
\hline & & Ri_af_scal_P & CAGATAGGAACAGTAATTGTAACGGAACCAG & & \\
\hline \multirow{3}{*}{ Rickettsiafelis } & \multirow{3}{*}{ orfB } & Ri_fel_orfB_F & ACCCTTTTCGTAACGCTTTGC & \multirow{3}{*}{163} & \multirow{3}{*}{ Culture } \\
\hline & & Ri_fel_orfB_R & TATACTTAATGCTGGGCTAAACC & & \\
\hline & & Ri_fel_orfB_P & AGGGAAACCTGGACTCCATATTCAAAAGAG & & \\
\hline \multirow{3}{*}{ Rickettsia typhi } & \multirow{3}{*}{ ompB } & Ri_typ_ompB_F & CAGGTCATGGTATTACTGCTCA & \multirow{3}{*}{133} & \multirow{3}{*}{ Culture } \\
\hline & & Ri_typ_ompB_R & GCAGCAGTAAAGTCTATTGATCC & & \\
\hline & & Ri_typ_ompB_P & ACAAGCTGCTACTACAAAAAGTGCTCAAAATG & & \\
\hline \multirow{3}{*}{ Rickettsia prowazekii } & & Ri_pro_gltA_F & CAAGTATCGGTAAAGATGTAATCG & & \\
\hline & gltA & Ri_pro_gltA_R & TATCCTCGATACCATAATATGCC & 151 & Plasmid \\
\hline & & Ri_pro_gtt_P & ATATAAGTAGGGTATCTGCGGAAGCCGAT & & \\
\hline & & Bo_bu_sl_23S_F & GAGTCTTAAAAGGGCGATTTAGT & & ${ }^{*}$, Culture of B.affeli, $B$. \\
\hline Borrelia spp. ${ }^{*}$ & 23SrRNA & Bo_bu_st-23S_R & CTTCAGCCTGGCCATAAATAG & 73 & garinï, B.valaisiana, $B$. \\
\hline & & Bo_bu_sl_23S_P & TAGATGTGGTAGACCCGAAGCCGAGT & & lusitaniae, B. recurrentis \\
\hline & & Bo_bu_glpA_F & GCAATTACAAGGGGGTATAAAGC & & \\
\hline $\begin{array}{l}\text { Borrelia burgaorfent } \\
\text { sensustricto }\end{array}$ & glpA & Bo_bu_gpA_R & GGCGTGATAAGTGCACATTCG & 206 & Culture \\
\hline & & Bo_bu_glpA_P & TTAATTAAACGGGGTGCATTCTTCTCAAGAATG & & \\
\hline & & Bor_ans_fla_F & GGAGCACAACAAGAGGGAG & & \\
\hline Borrelia anserina & fla & Bor_ans_fla_R & TTGGAGAATTAACCCCACCTG & 76 & Plasmid \\
\hline & & Bor_ans_fla_P & TGCAAGCAACTCCAGCTCCAGTAGCT & & \\
\hline
\end{tabular}




\begin{tabular}{|c|c|c|c|c|c|}
\hline \multirow{3}{*}{ Borrelialonestari } & \multirow{3}{*}{ glpQ } & Bor_lon_glpQ F & GATCCAGAACTTGATACAACCAC & \multirow{3}{*}{99} & \multirow{3}{*}{$\begin{array}{l}\text { Infected Amblyomma } \\
\text { americanum }\end{array}$} \\
\hline & & Bor_lon_glpQ R & TTCATCTAGTGAGAAGTCAGTAG & & \\
\hline & & Bor_lon_glpQ P & АGTAATATCGTCСGTCTTCCСТАGСTCG & & \\
\hline \multirow{3}{*}{ Borreliaparkeri } & \multirow{3}{*}{ gyrB } & Bor_par_gyrB_F & GCAAAACGATTCAAAGTGAGTCC & \multirow{3}{*}{184} & \multirow{3}{*}{ Culture } \\
\hline & & Bor_par_gyrB_R & CTCATTGCCTTTAAGAAACCACTT & & \\
\hline & & Bor_par_gyrB_P & TTAAAACCAGCAACATGAGTTCCTCCTTCTC & & \\
\hline \multirow{3}{*}{ Borreliabissettii* } & \multirow{3}{*}{ rpoB } & Bo_bi_rpoB_F & GCAACCAGTCAGCTTTCACAG & \multirow{3}{*}{118} & \multirow{3}{*}{ Plasmid } \\
\hline & & Bo_bi_rpoB_R & CAAATCCTGCCCTATCCCTTG & & \\
\hline & & Bo_bi_rpoB_P & AAAGTCCTCCCGGCCCAAGAGCATTAA & & \\
\hline \multirow{3}{*}{ Borrelia theileri } & \multirow{3}{*}{ glpQ } & Bo_th_glpQ F & GTGCTAACAAAGGACAATATTCC & \multirow{3}{*}{213} & \multirow{3}{*}{ Plasmid } \\
\hline & & Bo_th_glpQR & GGTTAGTGGAAAACGGTTAGGAT & & \\
\hline & & Bo_th_glpQP & TATTATAATTCACGAGCCAGAGCTTGACAC & & \\
\hline \multirow{3}{*}{ Bartonella spp. } & \multirow{3}{*}{ ssrA } & Bart_spp_ssrA_F & CGTTATCGGGCTAAATGAGTAG & \multirow{3}{*}{118} & \multirow{3}{*}{$\begin{array}{l}\text { *, Gulture of } B \text {. } \\
\text { quintana }\end{array}$} \\
\hline & & Bart_spp_ssrA_R & ACCCCGCTTAAACCTGCGA & & \\
\hline & & Bart_spp_ssrA_P & TTGCAAATGACAACTATGCGGAAGCACGTC & & \\
\hline \multirow{3}{*}{$\begin{array}{c}\text { Bartonella } \\
\text { barailiformis* }\end{array}$} & & Ba_ba_rpoB_F & GAAGAGTTTGTAGTTTGTCGTCA & & \\
\hline & rpoB & Ba_ba_rpoB_R & AGCAGCTACAGAAACCAACTG & 105 & Culture \\
\hline & & Ba_ba_poB_P & TGCAGGTGAAGITTTGATGGTGCCACG & & \\
\hline & & Bar_he_nibC_F & GGGATGCGATTTAATAGTTCTAC & & \\
\hline Bartonellahenselae & $\mathrm{ribC}$ & Bar_he_ribC_R & CGCTTGTTGTTTTGATCCTCG & 116 & Culture \\
\hline & & Bar_he_ribC_P & ACGTTATAGTAGCGAAAACTTAGAAATTGGTGC & & \\
\hline & & Bar_vin_IIS_F & GGAATTGCTTAACCCACTGTTG & & \\
\hline Bartonella vinsonm & IIS & Bar_vin_IIS_R & CCTTATTGATTTAGATCTGATGGG & 141 & Culture \\
\hline & & Bar_vin_IIS_P2 & AGAAACTCCCGCCTTTATGAGAGAAATCTCT & & \\
\hline & & Co_bu_icd_F & AGGCCCGTCCGTTATTTTACG & & \\
\hline & Ied & Co_bu_icd_R & CGGAAAATCACCATATTCACCTT & 74 & Gulture \\
\hline Coxiellaburnetii and & & Co_bu_icd_P & TTCAGGCGTTTTGACCGGGCTTGGC & & \\
\hline Coxiella-like* & & Co_bu_IS111_F & TGGAGGAGCGAACCATTGGT & & \\
\hline & IS1111 & Co_bu_IS111_R & CATACGGTTTGACGTGCTGC & 86 & Gulture \\
\hline & & Co_bu_IS111_P & ATCGGACGTTTATGGGGATGGGTATCC & & \\
\hline & & Fr_tu_tul4_F & ACCCACAAGGAAGTGTAAGATTA & & \\
\hline & tul4 & Fr_tu_tul4_R & GTAATTGGGAAGCTTGTATCATG & 76 & Culture \\
\hline Francisella tularensis & & Fr_tu_tul4_P & AATGGCAGGCTCCAGAAGGTTCTAAGT & & \\
\hline endosimbionts* & & Fr_tu_fopA_F & GGCAAATCTAGCAGGTCAAGC & & \\
\hline & fopA & Fr_tu_fopA_R & CAACACTTGCTTGAACATTTCTAG & 91 & Culture \\
\hline & & Fr_tu_fopA_P & AACAGGTGCTTGGGATGTGGGTGGTG & & \\
\hline & & Ana_spp_16S_F & CTTAGGGTTGTAAAACTCITTCAG & & \\
\hline Anaplasmaspp. & 16SrRNA & Ana_spp_16S_R & СТTТАAСТTAССАAАССGССТАС & 160 & ** \\
\hline & & Ana_spp_16S_P & ATGCCCTTTACGCCCAATAATTCCGAACA & & \\
\hline & & An_ma_msp1_F & CAGGCTTCAAGCGTACAGTG & & Experimentally \\
\hline marginale* & msplb & An_ma_msp1_R & GATATCTGTGCCTGGCCTTC & 85 & infected bovineblood \\
\hline & & An_ma_msp1_P & ATGAAAGCCTGGAGATGTTAGACCGAG & & sample \\
\hline & & An_ph_msp2_F & GCTATGGAAGGCAGTGTTGG & & \\
\hline $\begin{array}{c}\text { Anapiasma } \\
\text { phoogotonhilum * }\end{array}$ & msp2 & An_ph_msp2_R & GTCTTGAAGCGCTCGTAACC & 77 & Intected lxodes spp. \\
\hline & & An_ph_msp2_P & AATCTCAAGCTCAACCCTGGCACCAC & & \\
\hline & & An_pla_groEL_F & TTCTGCCGATCCTTGAAAACG & & \\
\hline Anaplasma platys* & groEL & An_pla_groEL_R & СТТСТССТТСТАСАТССТСАG & 75 & $\begin{array}{l}\text { inrected cannebiood } \\
\text { sample }\end{array}$ \\
\hline & & An_pla_groEL_P & TTGCTAGATCCGGCAGGCCTCTGC & & \\
\hline Ananlasmahoric* & $\mathrm{omFT}$ & An_bo_groEL_F & GGGAGATAGTACACATCCTTG & 73 & Plasm \\
\hline & & An_bo_groEL_R & CTGATAGCTACAGTTAAGCCC & 73 & \\
\hline
\end{tabular}




\begin{tabular}{|c|c|c|c|c|c|}
\hline & & An_bo_groEL_P & AGGTGCTGTTGGATGTACTGCTGGACC & & \\
\hline \multirow{3}{*}{ Anaplasmaovis* } & \multirow{3}{*}{ msp4 } & An_ov_msp4_F & TCATTCGACATGCGTGAGTCA & \multirow{3}{*}{92} & \multirow{3}{*}{ Plasmid } \\
\hline & & An_ov_msp4_r & TTTGCTGGCGCACTCACATC & & \\
\hline & & An_ov_msp4_P & AGCAGAGAGACCTCGTATGTTAGAGGC & & \\
\hline \multirow{3}{*}{ Ehrlichia spp.* } & \multirow{3}{*}{ 16SrRNA } & Neo_mik_16S_F & GCAACGCGAAAAACCTTACCA & \multirow{3}{*}{98} & \multirow{3}{*}{ * } \\
\hline & & Neo_mik_16S_R & AGCCATGCAGCACCTGTGT & & \\
\hline & & Neo_mik_16S_P & AAGGTCCAGCCAAACTGACTCTTCCG & & \\
\hline \multirow{3}{*}{ Ehrichiacanis } & \multirow{3}{*}{ gltA } & Eh_ca_gttA_F & GACCAAGCAGTTGATAAAGATGG & \multirow{3}{*}{136} & \multirow{3}{*}{ Culture } \\
\hline & & Eh_ca_gltA_R & CACTATAAGACAATCCATGATTAGG & & \\
\hline & & Eh_ca_gltA_P & ATTAAAACATCCTAAGATAGCAGTGGCTAAGG & & \\
\hline \multirow{3}{*}{ Ehrlichia chaffeensis * } & \multirow{3}{*}{ dsb } & Eh_dh_dsb_F & TATTGCTAATTACCCTCAAAAAGTC & \multirow{3}{*}{117} & \multirow{3}{*}{$\begin{array}{c}\text { Infected Amblyomma } \\
\text { americanum }\end{array}$} \\
\hline & & Eh_d__dsb_R & GAGCTATCCTCAAGTTCAGATTT & & \\
\hline & & Eh_dh_dsb_P & ATTGACCTCCTAACTAGAGGGCAAGCA & & \\
\hline \multirow{3}{*}{ Ehrlichia ewingö * } & \multirow{3}{*}{ dsb } & Eh_ew_dsb_F & CAATACTTGGAGAAGCATCATTG & \multirow{3}{*}{111} & \multirow{3}{*}{$\begin{array}{c}\text { Infected Amblyomma } \\
\text { americanum }\end{array}$} \\
\hline & & Eh_ew_dsb_R & TTGCTTATGGCTTAATGCTGCAT & & \\
\hline & & Eh_ew_dsb_P & AAAGCAGTACGTGCAGCATTGGCTGTA & & \\
\hline \multirow{3}{*}{$\begin{array}{c}\text { Ehrlichia } \\
\text { ruminantium }\end{array}$} & & Eh_ru_gltA_F & CCAGAAAACTGATGGTGAGTTAG & & \\
\hline & gltA & Eh_ru_gttA_R & AGCCTACATCAGCTTGAATGAAG & 116 & Culture \\
\hline & & Eh_ru_gttA_P & AGTGTAAACTTGCTGITGCTAAGGTAGCATG & & \\
\hline & & Eh_PME_gltA_F & GCTAGTTATGAGTTAGAATGTAAAC & & \\
\hline $\begin{array}{l}\text { Panola Mlountain } \\
\text { Fhrlichia }\end{array}$ & gltA & Eh_PME_gltA_R & TACTATAGGATAATCTTGAATCAGC & 121 & Inteded Amblyomma \\
\hline & & Eh_PME_gltA_P & TTGCTATCGCTAAAATTCCAAGTATGATTGCG & & \\
\hline & & Neo_mik_groEL_F & AGAGACATCATTCGCATTTTGGA & & \\
\hline Neoenrichna & groEL & Neo_mik_groEL_R & TTCCGGTGTACCATAAGGCTT & 96 & Intected rodentblood \\
\hline & & Neo_mik_groEL_P & AGATGCTGTTGGATGTACTGCTGGACC & & \\
\hline & & Ae_pul_groEL_F & AGCCAGTATTATCGCTCAAGG & & \\
\hline Aegyptanella & groEL & Ae_pul_groEL_R & GCCTCACGTGCCTTCATAAC & 168 & Plasmid \\
\hline & & Ae_pul_groEL_P & TGCTTCTCAGTGTAACGACAGGGTTGG & & \\
\hline & & Apic_18S_F & TGAACGAGGAATGCCTAGTATG & & * Infected canine \\
\hline & & Apic_18S_R & CACCGGATCACTCGATCGG & & blood sample, with $B$. \\
\hline Apicomplexa & 18SrRNA & & & 104 & canisrossi, B.caniscanis, \\
\hline & & Apic_18S_S & TAGGAGCGACGGGCGGTGTGTAC & & Culture of $B$.divergens, \\
\hline & & & & & T.lestoquari, T.anmulata \\
\hline & & Ba_vo_hsp70_F & TCACTGTGCCTGCGTACTTC & & \\
\hline Babesia canis zogeli* & hsp70 & Ba_vo_hsp70_R & TGATACGCATGACGITGAGAC & 87 & $\begin{array}{l}\text { Intected canineblood } \\
\text { sample }\end{array}$ \\
\hline & & Ba_vo_hsp70_P & AACGACTCCCAGCGCCAGGCCAC & & \\
\hline & & Ba_ov_18S_F & TCTGTGATGCCCTTAGATGTC & & \\
\hline Babesia oris* & 18SrRNA & Ba_ov_18S_R & GCTGGTTACCCGCGCCTT & 92 & Plasmid \\
\hline & & Ba_ov_18S_P & TCGGAGCGGGGTCAACTCGATGCAT & & \\
\hline & & Ba_big_RNA18S_F & ATTCCGTTAACGAACGAGACC & & \\
\hline Babesiabigemina * & 18SrRNA & Ba_big_RNA18S_R & TTCCCCCACGCTTGAAGCA & 99 & Plasmid \\
\hline & & Ba_big_RNA18S_P & CAGGAGTCCCTCTAAGAAGCAAACGAG & & \\
\hline & & Ba_gib_rap1_F & СTCTTGCTCATCATCTTTTCGG & & \\
\hline Babesia gibsoni & Rap1 & Ba_gib_rap1_R & TCAGCGTATCCATCCATTATATG & 130 & Plasmid \\
\hline & & Ba_gib_rap1_S & TTTAATGCGTGCTACGTTGTACTTCCCAAAG & & \\
\hline & & Ba_cab_rap1_F & GTTGTTCGGCTGGGGCATC & & \\
\hline Babesia caballi* & Rap1 & Ba_cab_rap1_R & CAGGCGACTGACGCTGTGT & 94 & Plasmid \\
\hline & & Ba_cab_rap1_P & TCTGTCCCGATGTCAAGGGGCAGGT & & \\
\hline & & Ba_bo_CCTeta_F & GCCAAGTAGTGGTAGACTGTA & & \\
\hline Babesiaboris* & CCTeta & Ba_bo_CCTeta_R & GCTCCGTCATTGGTTATGGTA & 100 & Plasmid \\
\hline & & Ba_bo_CCTeta_P & TAAAGACAACACTGGGTCCGCGTGG & & \\
\hline
\end{tabular}




\begin{tabular}{|c|c|c|c|c|c|}
\hline \multirow{3}{*}{ Babesiaduncani* } & \multirow{3}{*}{ IIS2 } & Ba_du_ITS F F & ATTTCCGTTTGCGAGAGTTGC & \multirow{3}{*}{87} & \multirow{3}{*}{ Plasmid } \\
\hline & & Ba_du_ITS_R & AGGAAGCATCAAGTCATAACAAC & & \\
\hline & & Ba_du_ITS_P & AACAAGAGGCCCCGAGATCAAGGCAA & & \\
\hline \multirow{3}{*}{ Babesia microti* $^{*}$} & \multirow{3}{*}{ CCTeta } & Bab_mi_CCTeta_F & ACAATGGATTTTCCCCAGCAAAA & \multirow{3}{*}{145} & \multirow{3}{*}{ Culture } \\
\hline & & Bab_mi_CCTeta_R & GCGACATTTCGGCAACTTATATA & & \\
\hline & & Bab_mi_CCTeta_P & TACTCTGGTGCAATGAGCGTATGGGTA & & \\
\hline \multirow{3}{*}{ Theileriaparza* } & \multirow{3}{*}{ 18SrRNA } & Th_pa_18S_F & GAGTATCAATTGGAGGGCAAG & \multirow{3}{*}{173} & \multirow{3}{*}{ Culture } \\
\hline & & Th_pa_18S_R & CAGACAAAGCGAACTCCGTC & & \\
\hline & & Th_pa_18S_P & AAATAAGCCACATGCAGAGACCCCGAA & & \\
\hline \multirow{3}{*}{ Theileria mutans } & \multirow{3}{*}{ IIS } & The_mu_IIS_F & CCTTATTAGGGGCTACCGTG & \multirow{3}{*}{119} & \multirow{3}{*}{ Plasmid } \\
\hline & & The_mu_IIS_R & GTTCAAATTTGAAGTAACCAAGTG & & \\
\hline & & The_mu_IIS_P & ATCCGTGAAAAACGTGCCAAACTGGITAC & & \\
\hline \multirow{3}{*}{ Theileriazelifera } & \multirow{3}{*}{ 18SrRNA } & The_ve_18S_F & TGTGGCITATCTGGGTTCGC & \multirow{3}{*}{151} & \multirow{3}{*}{ Plasmid } \\
\hline & & The_ve_18S_R & ССАTTACITTGGTACСТАAAACC & & \\
\hline & & The_ve_18S_P & TTGCGTTCCCGGTGTTTTACTTTGAGAAAG & & \\
\hline \multirow{3}{*}{ Theileriaequi } & & Th_eq_ema1_F4 & CGGCAAGAAGCACACCTTC & & \\
\hline & emal & Th_eq_ema1_R4 & TGCCATCGCCCITGTAGAG & 167 & Plasmid \\
\hline & & Th_eq_ema1_P4 & AAGGCTCCAGGCAAGCGCGTCCT & & \\
\hline & & Cy_fel_IIS2_F & AAGATCCGAACGGAGTGAGG & & \\
\hline Cytauxzoon felis & IIS2 & Cy_fel_IIS2_R & GTAGTCTCACCCAATTTCAGG & 119 & Plasmid \\
\hline & & Cy_fel_IIS2_S & AAGTGTGGGATGTACCGACGTGTGAG & & \\
\hline & & Hepa_spp_18S_F & ATTGGCTTACCGTGGCAGTG & & \\
\hline Hepatozoon spp. & 18SrRNA & Hepa_spp_18S_R & AAAGCATTTTAACTGCCTTGTATTG & 175 & ** \\
\hline & & Hepa_spp_18S_S & ACGGTTAACGGGGGATTAGGGITCGAT & & \\
\hline & & He_can_18S_F & TTCTAACAGTTTGAGAGAGGTAG & & \\
\hline Hepatozoon canis & 18SrRNA & He_can_18S_R & AGCAGACCGGTTACTTTTAGC & 221 & \\
\hline & & He_can_18S_S & AGAACTTCAACTACGAGCTTTTTAACTGCAAC & & \\
\hline & & He_ame_18S_F2 & GGTATCATTTTGGTGTGTTTTTAAC & & \\
\hline Hepatozoon & 18SrRNA & He_ame_18S_R2 & CTTATTATTCCATGCTCCAGTATTC & 159 & Plasmid \\
\hline & & He_ame_18S_P2 & AAAAGCGTAAAAGCCTGCTAAAAACACTCTAC & & \\
\hline & & Leish_spp_hsp70_F & CGACCTGTTCCGCAGCAC & & \\
\hline Leishmaniaspp. & hsp70 & Leish_spp_hsp70_R & TCGTGCACGGAGCGCTTG & 78 & \\
\hline & & Leish_spp_hsp70_S & TCCATCTTCGCGTCCTGCAGCACG & & \\
\hline & & Le_inf_ITS_F & CGCACCGCCTATACAAAAGC & & \\
\hline Lelshimantal & IIS & Le_inf_ITS_R & GTTATGTGAGCCGTTATCCAC & 108 & Culture \\
\hline & & Le_inf_IIS_S & ACACGCACCCACCCCGCCAAAAAC & & \\
\hline & & Ra_vit_18S_F & TAACCGTGCTAATTGTAGGGC & & \\
\hline Rangelia vitalii & 18SrRNA & Ra_vit_18S_R & GAATCACCAAACCAAATGGAGG & 92 & Plasmid \\
\hline & & Ra_vit_18S_S & TAATACACGITCGAGGGCGCGTTTTGC & & \\
\hline & & Tick_spp_16S_F & AAATACTCTAGGGATAACAGCGT & & \\
\hline Tickspp. & 16SrRNA & Tick_spp_16S_R & TCTTCATCAAACAAGTATCCTAATC & 99 & * \\
\hline & & Tik__spp_16S_P & CAACATCGAGGTCGCAAACCATTTTGTCTA & & \\
\hline & & Amb_var_IIS2_F & GCCAGCCTCTGAAGTGACG & & \\
\hline Amoryomina & IIS2 & Amb_var_IIS2_R & TTCTGCGGTTTAAGCGACGC & 117 & lickextract \\
\hline & & Amb_var_IIS2_P & TCTTGCCACTCGACCCGTGCCTC & & \\
\hline & & Rhi_mic_IIS2_F & GCTTAAGGCGTTCTCGTCG & & \\
\hline Kripicepnalus & IIS2 & Rhi_mic_IIS2_R & CAAGGGCAGCCACGCAG & 144 & Mckexuract \\
\hline & & Rhi_mic_IIS2_P & TAGTCCGCCGTCGGTCTAAGTGCITC & & \\
\hline & $\pi S$ & Rhi_san_IIS2_F & TTGAACGCTACGGCAAAGCG & 110 & Tidisortmet (Tmpo) \\
\hline & & Rhi_san_IIS2_R & CCATCACCTCGGTGCAGTC & 110 & 1ukexurad(rianine) \\
\hline
\end{tabular}


Rhipicephalus sanguineus sensu

lato

The detection ability of each design and the effect of pre-amplification on detection signals were first checked by TaqMan real-time PCR on a LightCycler 480 apparatus using a range of dilutions of positive controls (Table 1, Table S1). Three kinds of positive controls were used, including bacterial or protozoan cultures when available, DNA from infected ticks or blood samples, and plasmidic constructions as a last resort (Table 1). Except for the design targeting Borrelia burgdorferi sensu stricto, which never succeeded in detecting the positive controls even after a pre-amplification step, the remaining 60 designs targeting TBPs and tick species were able to detect their target with $\mathrm{Ct}$ values between 6 and 38 (data not shown). Pre-amplification improved the quality of detection and was, therefore, validated as part of the screening protocol (see Figure S1). The relative specificity of the 61 designs was then evaluated using the BioMark system and a total of 62 positive controls (Figure 1, Table S1).

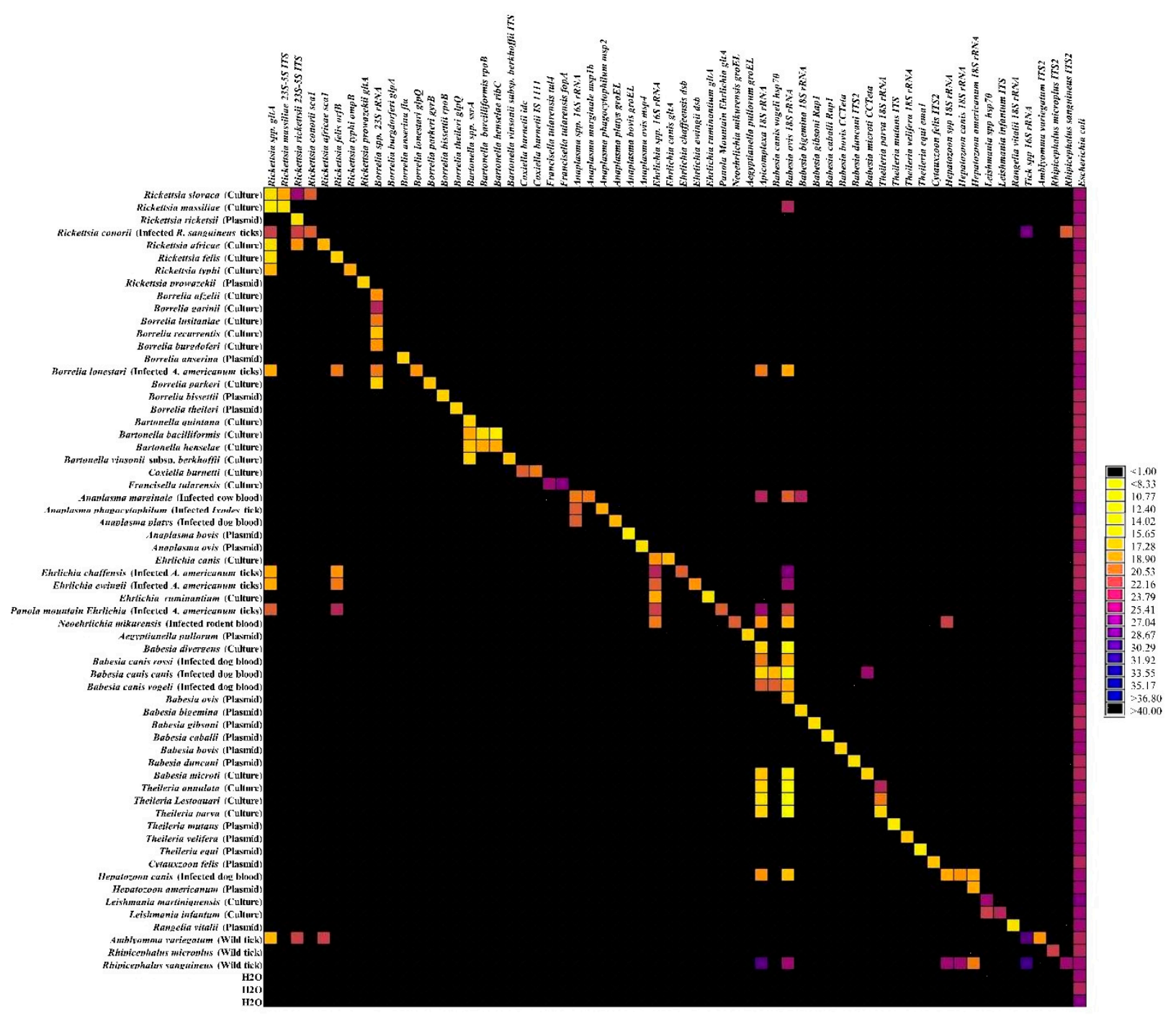

Figure 1. BioMark ${ }^{\mathrm{TM}}$ dynamic array system specificity test (96.96 chip). Each square corresponds to a single real-time PCR reaction, where rows indicate the pathogen in the sample and columns represent the target of the primer/probe set. Ct values for each reaction are represented by a color gradient; the color scale is shown on the right y-axis. The darkest shades of blue and black squares are considered as negative reactions with $\mathrm{Ct}>30$. 
Forty-three primer/probe sets were able to specifically detect and amplify their target using a $\mathrm{Ct}$ cut-off value of 30; they were then directly validated (Figure 1). The remaining designs were able to detect and amplify their target, but they also gave positive results in outgroup controls. Interestingly, two kinds of unsuspected signals were observed: some were related to cross-reactions with closely related species and some to potential co-infections in controls corresponding to field samples (Figure 1). Thus, eight designs-Rickettsia massiliae, Rickettsia conorii, Bartonella henselae, Bartonella bacilliformis, Babesia canis vogeli, Babesia microti, Theileria parva and Hepatozoon americanum-gave positive results in outgroup controls, revealing cross-reactions with one to two closely related species (Figure 1). Caution will be required when interpreting results obtained with these designs. Seven designsRickettsia spp., Rickettsia felis, Rickettsia africae, Apicomplexa, Babesia bigemina, Hepatozoon spp. and Hepatozoon canis-gave positive results in outgroup controls linked to potential co-infection in controls corresponding to DNA from infected ticks or blood samples (Figure 1). As co-infections may occur in natural tick or blood samples, these unexpected detections in biological samples were likely due to the natural (co)occurrence of microorganisms rather than to cross-reactions. Finally, the Babesia ovis and Rickettsia rickettsii designs gave multiple cross-reactions with closely related species or distant outgroups and, thus, were considered as non-specific and removed from the rest of the study (Figure 1). More details on the relative specificity analysis of the designs are available in Appendix A.

To conclude, with the exception of the sets of primers and probes targeting Borrelia burgdorferi sensu stricto, Babesia ovis and Rickettsia rickettsii that were ultimately removed from the study, the 58 remaining designs were validated for the high-throughput screening of pathogens in Caribbean ticks, taking into account the notified cross-reactions.

\subsection{Large-scale TBP Detection Survey in Ticks from Guadeloupe and Martinique}

A total of 578 adult ticks were collected from cattle in Guadeloupe and Martinique. In total, 523 samples were tested using the BioMarkTM system developed in this study. The molecular identification of Amblyomma variegatum and Rhipicephalus microplus using the corresponding specific designs were consistent with the morphological identification made after tick collection. The number of positive ticks and the corresponding infection rates for each detected pathogen were calculated for 132 A. variegatum as well as 165 and 281 R. microplus specimens from Guadeloupe and Martinique, respectively (Figure 2). As some of the R. microplus samples corresponded to pools of two to four adult specimens, we reported the minimum and maximum infection rates (see Materials and Methods). 


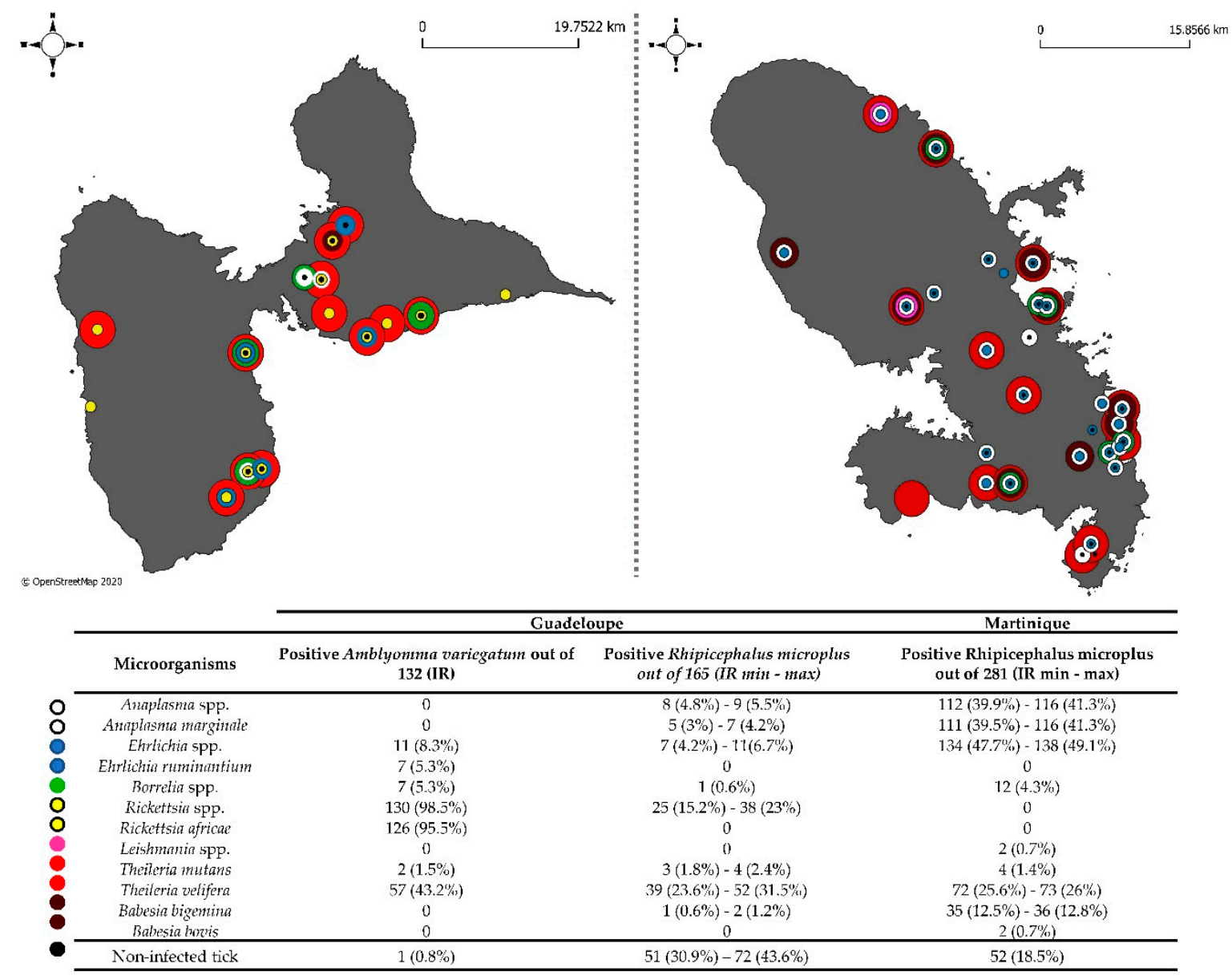

Figure 2. Infection rates in ticks collected in Guadeloupe and Martinique. Number of positive $A$. variegatum ticks (out of 132) and R. microplus ticks from Guadeloupe (out of 165) and Martinique (out of 281). On the maps, black dots indicate the collection sites of non-infected tick samples and colored dots indicate the collection sites of infected tick samples; The dot color determine the bacterial and parasitic genus of the microorganism found as indicated in the table; IR: Infection rate. As some $R$. microplus samples were pooled, we have presented minimum and maximum tick infection rates. .

Conventional PCRs/nested PCRs followed by amplicon sequencing were performed on several tick samples presenting low $\mathrm{Ct}$ values to confirm the results of the newly designed BioMark ${ }^{\mathrm{TM}}$ system (see Materials and Methods section). Identity percentages of the sequences obtained with reference sequences available in GenBank (NCBI) are presented in Table 2. 
Table 2. Homology between the deposited sequences and reference sequences in GenBank (T: Sample number tested by conventional assay; S: Sample number which allowed sequence recovery; AN: Accession number of the recovered sequence; L: recovered sequence length (bp); Id\%: percentage of nucleotide identity between recovered and reference sequences).

\begin{tabular}{|c|c|c|c|c|c|c|c|c|}
\hline Biomark Id & Sequence Name & $\mathrm{T}$ & $\mathrm{S}$ & $\overline{\mathrm{AN}}$ & $\mathrm{L}$ & Closest Homology & Id\% & Reference \\
\hline Rickettsia spp. & Rickettsia africae Tick208 & 30 & 14 & MK049851 & 248 & Rickettsia africae & 100 & AF123706.1 \\
\hline \multirow[t]{2}{*}{ Leishmania spp. } & $\begin{array}{c}\text { Leishmania martiniquensis } \\
\text { Tick389 }\end{array}$ & 2 & 1 & МК049850 & 272 & Leishmania martiniquensis & 100 & AF303938.1 \\
\hline & & & & & & Leishmania siamensis & 100 & GQ226033.1 \\
\hline \multirow[t]{4}{*}{ Borrelia spp. } & Borrelia sp. Tick7 & 30 & 1 & MK049846 & 245 & Borrelia anserina & 90 & X75201.1 \\
\hline & Borrelia sp. Tick457 & & 4 & МK049847 & 327 & Borreliasp. BR & 100 & EF141022.1 \\
\hline & & & & & & $\begin{array}{l}\text { Borrelia sp. strain Mo063b- } \\
\text { flaB }\end{array}$ & 100 & KY070335.1 \\
\hline & & & & & & Borrelia theileri & 99 & KF569936.1 \\
\hline Anaplasma spp. & Anaplasma sp. Tick314 & 2 & 2 & МК049845 & 245 & $\begin{array}{c}\text { Candidatus Anaplasma } \\
\text { boleense }\end{array}$ & 100 & KX987335.1 \\
\hline \multirow[t]{5}{*}{$\begin{array}{c}\text { Anaplasma } \\
\text { marginale }\end{array}$} & Anaplasma sp. Tick283 & 2 & 2 & МК049844 & 244 & Anaplasma marginale & 100 & MH155593.1 \\
\hline & & & & & & Anaplasma centrale & 100 & MF289482.1 \\
\hline & & & & & & Anaplasma ovis & 100 & MG770440.1 \\
\hline & & & & & & Anaplasma capra & 100 & MF000917.1 \\
\hline & & & & & & Anaplasma phagocytophilum & 100 & DQ648489.1 \\
\hline \multirow[t]{6}{*}{ Ehrlichia spp. } & Ehrlichia sp. Tick428 & 2 & 2 & МК049849 & 246 & Ehrlichia spp. & 100 & KY594915.1 \\
\hline & & & & & & Ehrlichia canis & 99 & KY594915.1 \\
\hline & & & & & & Ehrlichia ewingii & 99 & U96436.1 \\
\hline & & & & & & Ehrlichia chaffeensis & 99 & NR_074500.2 \\
\hline & & & & & & Ehrlichia muris & 99 & KŪ535865.1 \\
\hline & & & & & & Ehrlichia minasensis & 99 & NR_148800.1 \\
\hline $\begin{array}{l}\text { Ehrlichia } \\
\text { ruminantium }\end{array}$ & $\begin{array}{c}\text { Ehrlichia ruminantium } \\
\text { Tick116 }\end{array}$ & 1 & 1 & МК049848 & 207 & Ehrlichia ruminantium & 100 & NR_074155.1 \\
\hline Babesiabigemina & Babesiabigemina Tick222 & 2 & 1 & MK071738 & 99 & Babesiabigemina & 100 & KР710227.1 \\
\hline Babesiaboris & Babesia bovis Tick497 & 2 & 2 & MK071739 & 100 & Babesiabovis & 99 & AB367921.1 \\
\hline
\end{tabular}

2.2.1. Detection of Known TBPs in Caribbean Ticks

Seven TBPs known to circulate in the Caribbean were detected in ticks from Guadeloupe and Martinique: $R$. africae, E. ruminantium, A. marginale, B. bigemina, B. bovis, T. mutans and T. velifera (Figure 2).

Rickettsia spp. were only detected in ticks collected in Guadeloupe (Figure 2). R. africae was identified in $95.5 \%$ of the A. variegatum samples (Figure 2). In contrast, Rickettsia spp. detected in $15.2 \%-23 \%$ of the R. microplus samples from Guadeloupe were not directly identified as $R$. africae with the BioMark ${ }^{\mathrm{TM}}$ system (Figure 2). Thus, 14 A. variegatum (6/14) and $R$. microplus (8/14) samples positive for Rickettsia spp. were tested by nested PCR with primers targeting the ompB gene; this was followed by sequencing. All the sequences recovered were identical and displayed $100 \%$ identity with $R$. africae, confirming that the Rickettsia spp. detected in R. microplus from Guadeloupe corresponded also to R. africae. (Table 2). The consensus sequence was deposited under the name Rickettsia africae Tick208 (accession number MK049851).

E. ruminantium was identified in $5.3 \%$ of the A. variegatum ticks from Guadeloupe (Figure 2). We confirmed the presence of E. ruminantium nucleic acids by testing one sample of $A$. variegatum by conventional PCR targeting the $16 \mathrm{~S}$ rRNA genes; this was followed by amplicon sequencing. The sequence obtained displayed $100 \%$ sequence identity with E. ruminantium and was deposited under the name Ehrlichia ruminantium Tick116 (accession number MK049848) (Table 2). 
A. marginale was identified in R. microplus ticks from both islands, with infection rates reaching $3 \%-4.2 \%$ and $39.9 \%-41.3 \%$ of specimens from Guadeloupe and Martinique, respectively (Figure 2). We confirmed the detection of $A$. marginale by testing two samples of $R$. microplus by conventional PCR targeting the 16S rRNA genes; this was followed by amplicon sequencing. We obtained two identical sequences, deposited under the name Anaplasma sp. Tick283 (accession number MK049844), which displayed $100 \%$ sequence identity with Anaplasma spp. including A. marginale (Table 2).

B. bigemina was detected in $0.6 \%-1.2 \%$ and $12.5 \%-12.8 \%$ of the $R$. microplus ticks from Guadeloupe and Martinique, respectively (Figure 2). B. bovis was only detected in ticks from Martinique, with an infection rate of $0.7 \%$ in R. microplus samples (Figure 2). As conventional and nested PCR did not succeed in detecting these parasites, we directly sequenced amplicons obtained with the B. bigemina and B. bovis designs developed here, and corresponding sequences were identified (accession numbers MK071738 and MK071739 respectively) (Table 2).

T. velifera and T. mutans were detected in both tick species and on both islands. T. velifera was identified in $42.3 \%$ of the $A$. variegatum samples and in $23.6 \%-31.5 \%$ and $25.6 \%-26 \%$ of the $R$. microplus samples from Guadeloupe and Martinique, respectively (Figure 2). Moreover, T. mutans was detected in $1.5 \%$ of the A. variegatum samples and in $1.8 \%-2.4 \%$ and $1.4 \%$ of the $R$. microplus samples from Guadeloupe and Martinique, respectively (Figure 2). Unfortunately, neither conventional PCR nor BioMark amplicon sequencing succeeded in confirming the BioMark results.

\subsubsection{Detection of Unexpected Microorganisms in Caribbean Ticks}

Unexpected signals were obtained during the screening of microorganisms in ticks from Guadeloupe and Martinique, including the first detection of untargeted species belonging to the genera Anaplasma, Ehrlichia, Borrelia and Leishmania (Figure 2).

Ehrlichia spp. were detected in R. microplus ticks from both islands, with infection rates reaching $4.2 \%-6.6 \%$ and $47.7 \%-49.1 \%$ in Guadeloupe and Martinique, respectively (Figure 2). We tested two of the Ehrlichia spp.-positive R. microplus samples by conventional PCR targeting the 16S rRNA genes in order to identify the Ehrlichia spp. present in the Caribbean sample. We obtained two identical sequences, deposited under the name Ehrlichia sp. Tick428 (accession number MK049849) (Table 2). Phylogenetic and genetic distance analyses were performed using a portion of the 16S rRNA genes of several Ehrlichia species (Figure 3). The Ehrlichia sp. Tick428 sequence was found within a cluster including various uncharacterized Ehrlichia species detected in ticks from Asia and Africa (Figure 3). 


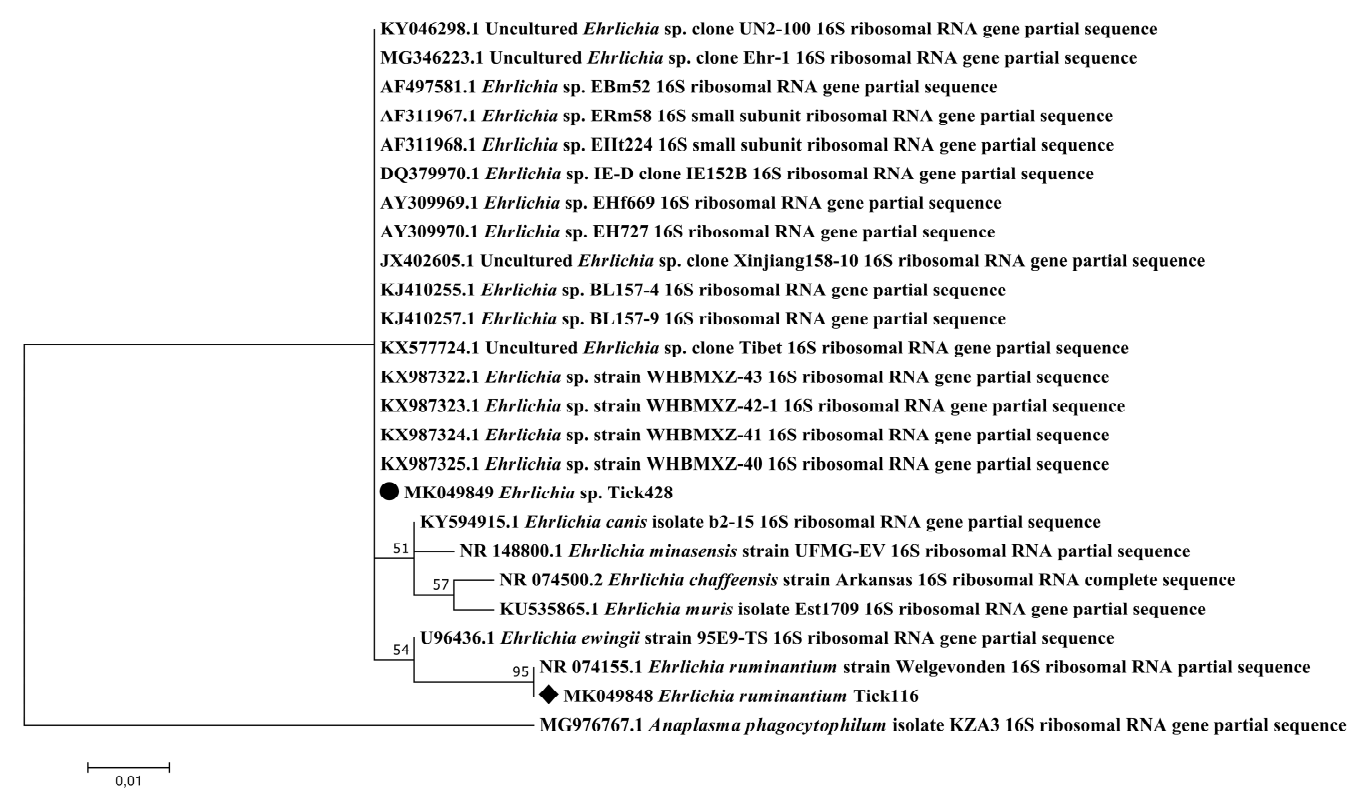

Figure 3. Phylogenetic analysis of $16 \mathrm{~S}$ rRNA sequences of Ehrlichia spp. Phylogenetic analysis of $16 \mathrm{~S}$ rRNA sequences of Ehrlichia spp. using the maximum likelihood method based on the Tamura-Nei model. In the phylogenetic tree, GenBank sequences, species designations and strain names are given. The sequences investigated in the present study are marked with a black circle (Ehrlichia sp. Tick428, accession number MK049849) and a black diamond (Ehrlichia ruminantium Tick116, accession number MK049848). The tree with the highest log likelihood (-413.76) is shown. The percentage of trees in which the associated taxa clustered together is shown above the branches (bootstrap values). The analysis involved 25 nucleotide sequences. There were a total of 206 positions in the final dataset.

In addition, in around 50\% (at least 4/8 ticks) and 18\% (at least 22/114 ticks) of the R. microplus specimens positive for Anaplasma spp., none of the Anaplasma species targeted by the BioMark ${ }^{\mathrm{TM}}$ system gave signals, suggesting the presence of an unexpected or new Anaplasma spp. (Figure 2). We tested two of the Anaplasma spp.-positive R. microplus samples by conventional PCR targeting the $16 \mathrm{~S}$ rRNA genes. We obtained two identical sequences, deposited under the name Anaplasma sp. Tick314 (accession number MK049845) (Table 2). This sequence displayed 100\% sequence identity with Candidatus Anaplasma boleense. Phylogenetic and genetic distance analyses were performed using a portion of the 16S rRNA genes of several Anaplasma species (Figure 4). The Anaplasma sp. Tick314 sequence was found in a cluster including Candidatus Anaplasma boleense, Anaplasma platys and Anaplasma phagocytophilum. 


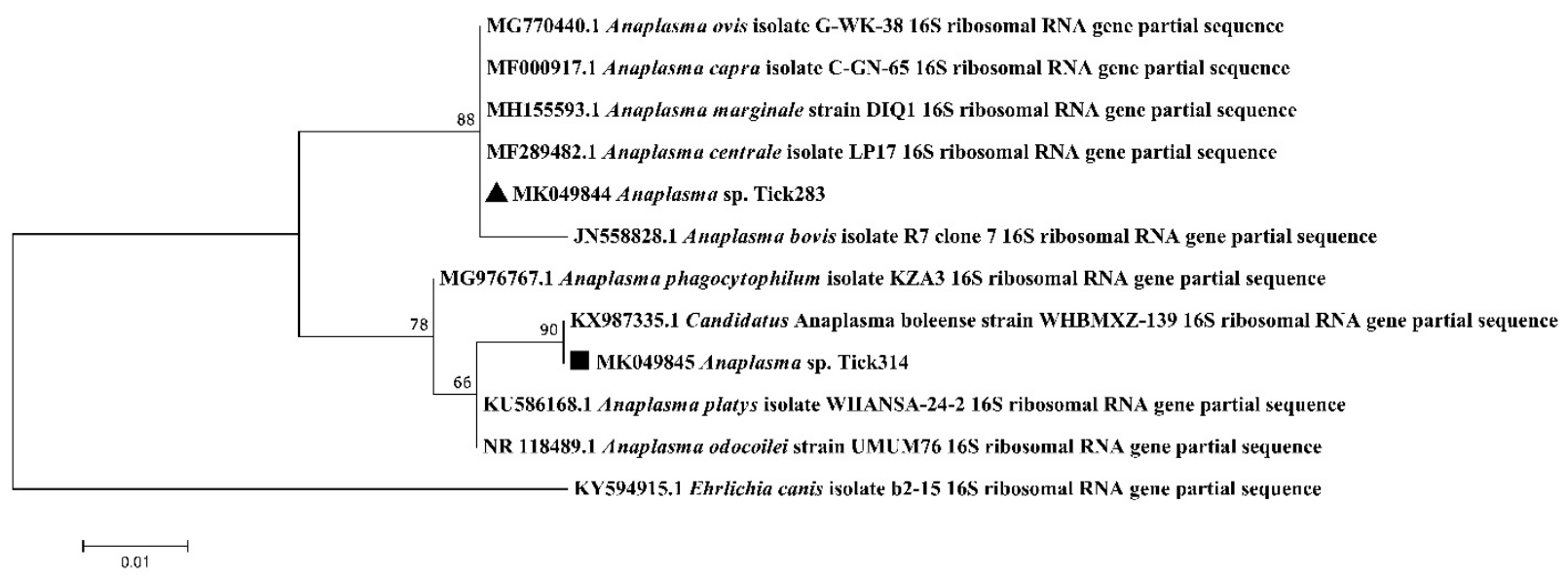

Figure 4. Phylogenetic analysis of $16 \mathrm{~S}$ rRNA sequences of Anaplasma spp. Phylogenetic analysis of $16 \mathrm{~S}$ rRNA sequences of Anaplasma spp. using the maximum likelihood method based on the TamuraNei model. In the phylogenetic tree, GenBank sequences, species designations and strain names are given. The sequences investigated in the present study are marked with a black triangle (Anaplasma sp. Tick283, accession number MK049844) and a black square (Anaplasma sp. Tick314, accession number MK049845). The tree with the highest log likelihood (-473.44) is shown. The percentage of trees in which the associated taxa clustered together is shown above the branches (bootstrap values). The analysis involved 12 nucleotide sequences. There were a total of 243 positions in the final dataset.

Borrelia spp. were detected in both tick species from both islands (Figure 2). Infection rates reached $5.3 \%$ in A. variegatum and $0.6 \%$ and $4.3 \%$ in R. microplus from Guadeloupe and Martinique, respectively (Figure 2). None of the specific targeted Borrelia species causing Lyme disease (Borrelia burgdorferi sensu lato), or the Borrelia relapsing fever group, gave any positive results, suggesting the occurrence of a new or unexpected Borrelia spp. in our samples (Figure 2). We tested 30 of the Borrelia spp.-positive ticks by nested PCR targeting the flaB genes. Interestingly, we obtained two sequences according to the tick species analyzed. The Borrelia sp. Tick7 (accession number MK049846) sequence was recovered from one A. variegatum sample from Guadeloupe, and the Borrelia sp. Tick457 sequence (accession number MK049847) was recovered from four R. microplus samples from Martinique (Table 2). Phylogenetic and genetic distance analyses were performed using a portion of the flaB gene of several Borrelia species (Figure 5). Surprisingly, the Borrelia sp. Tick7 sequence recovered from the $A$. variegatum sample, and found to be closely related to $B$. anserina, displayed an intermediate position, sharing homology with both the relapsing fever and Lyme disease groups (Figure 5). Lastly, the Borrelia sp. Tick457 sequence recovered from the $R$. microplus samples confirmed the previous observations, forming a cluster with various relapsing fever Borrelia species encountered in hard ticks, including B. lonestari and B. theileri (Figure 5). 


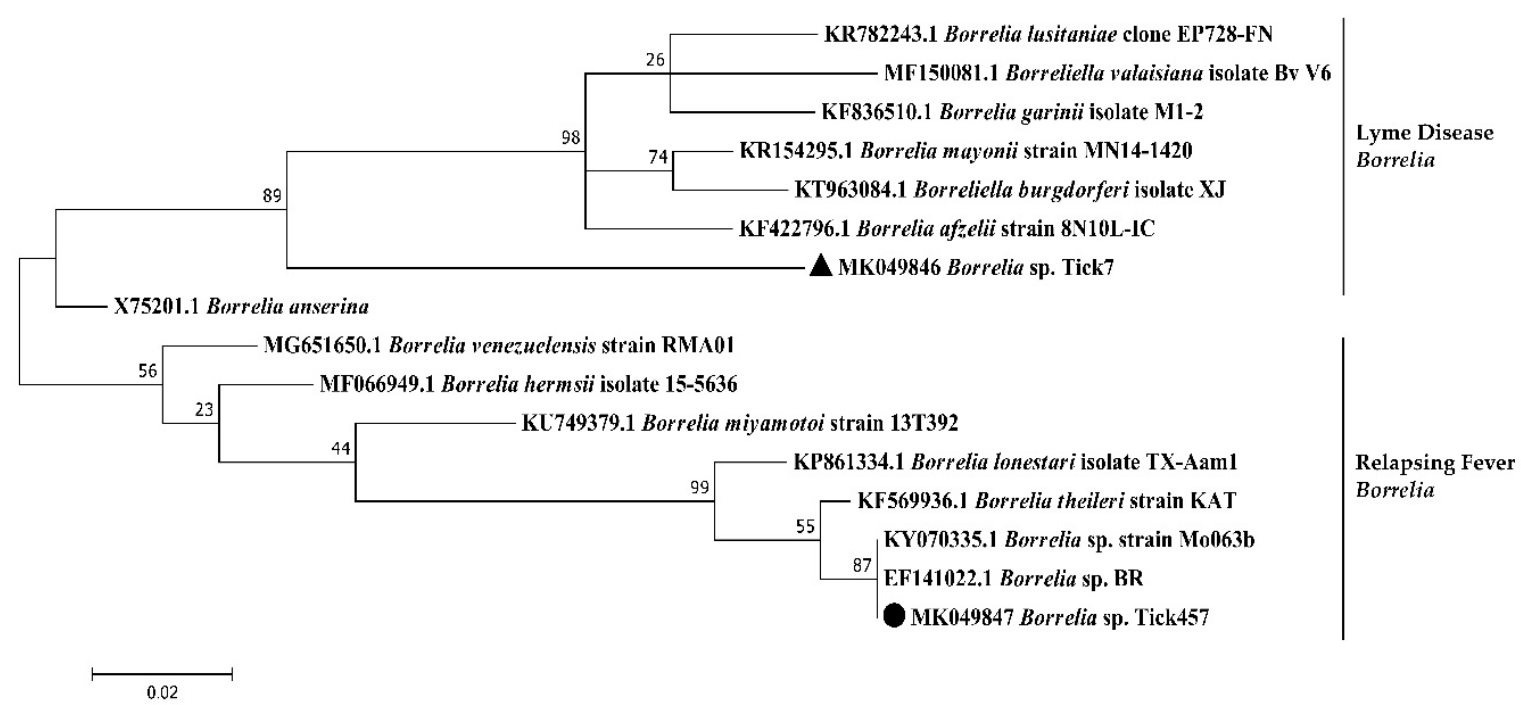

Figure 5. Phylogenetic analysis of flaB sequences of Borrelia spp. Phylogenetic analysis of flaB sequences of Borrelia spp. using the maximum likelihood method based on the Tamura-Nei model. In the phylogenetic tree, GenBank sequences, species designations and strain names are given. The sequences investigated in the present study are marked with a black circle (Borrelia sp. Tick457, accession number MK049847) and a black triangle (Borrelia sp. Tick7, accession number MK049846). The Lyme disease and relapsing fever clades of Borrelia are marked. The tree with the highest log likelihood (-963.24) is shown. The percentage of trees in which the associated taxa clustered together is shown above the branches (bootstrap values). The analysis involved 16 nucleotide sequences. There was a total of 245 positions in the final dataset.

Lastly, $0.7 \%$ of the R. microplus ticks from Martinique were positive for Leishmania spp. (Figure 2). We tested two of the Leishmania spp.-positive ticks by nested PCR targeting the small subunit rRNA gene. We obtained one sequence from one sample, deposited under the name Leishmania martiniquensis Tick389 (accession number MK049850) (Table 2). This sequence displayed 100\% identity with both the Leishmania martiniquensis and Leishmania siamensis sequences (Table 2).

\subsubsection{Co-infections in Ticks in Guadeloupe and Martinique}

We analyzed the co-infections observed in Amblyomma variegatum ( $\mathrm{n}=132$ samples), Rhipicephalus microplus collected in Guadeloupe $(\mathrm{n}=116$ samples, including individual and pooled specimens) and Martinique ( $\mathrm{n}=275$ samples, including individual and pooled specimens). In Guadeloupe, almost all of the A. variegatum samples (99.2\%) were infected with at least one pathogen, whereas only $56 \%$ of the R. microplus samples were infected (Figure 6, Table A3). In contrast, $81 \%$ of the R. microplus from Martinique were infected with at least one pathogen (Figure 6, Table A3). High and similar percentages of the two tick species were infected with either one or two pathogens. The percentages drastically dropped for co-infection with three pathogens, with less than $10 \%$ of the ticks infected. Respectively one and nine A. variegatum and R. microplus, from Guadeloupe and Martinique, were co-infected with four pathogens, and one R. microplus from Martinique was found infected with five pathogens (Figure 6, Table A3). 


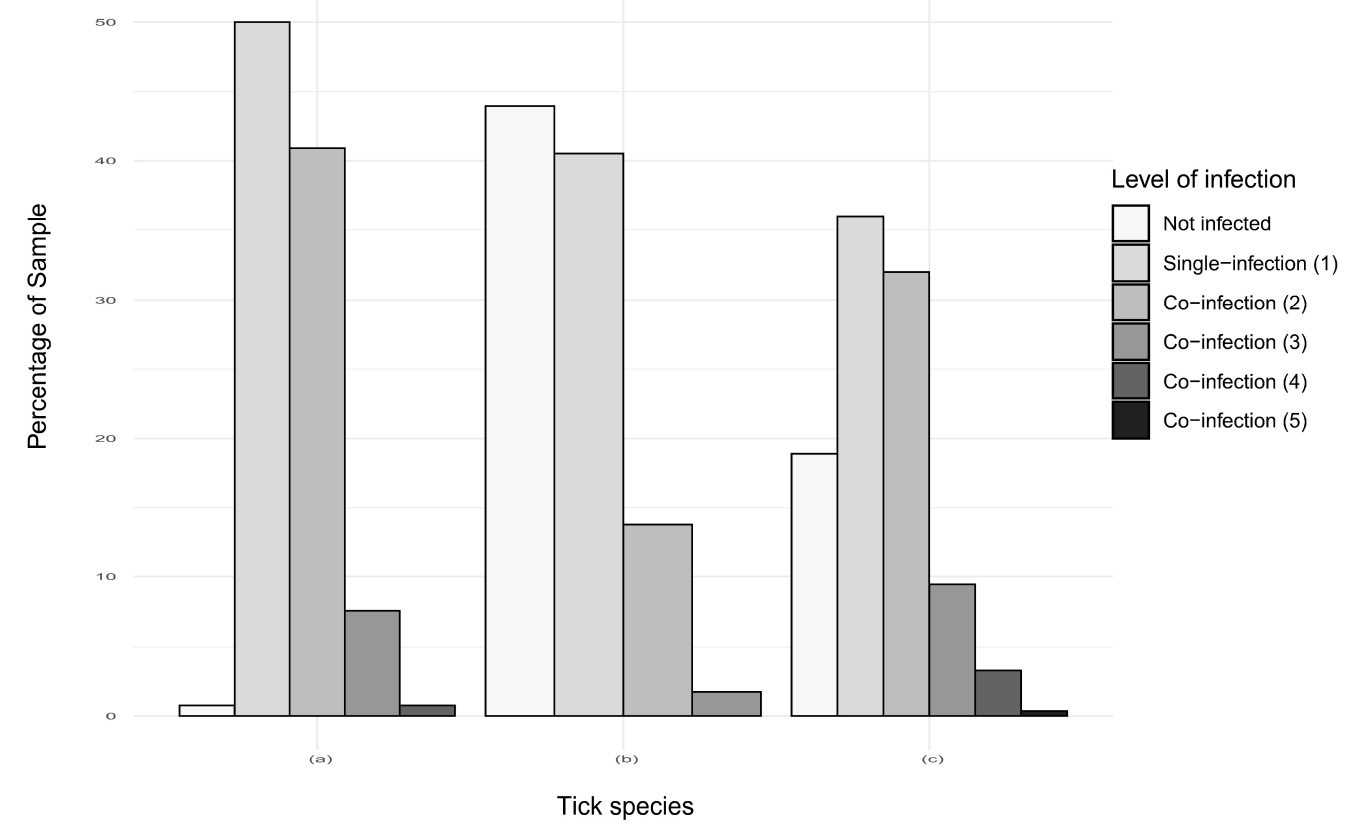

Figure 6. Co-infections detected in (a) Amblyomma variegatum ( $\mathrm{n}=132$ samples) and (b) Rhipicephalus microplus collected in Guadeloupe ( $\mathrm{n}=116$ samples) and (c) Rhipicephalus microplus collected in Martinique ( $\mathrm{n}=275$ samples).

A. variegatum from Guadeloupe were find heavily infected by R. africae, yet it did not seem to affect the presence of other pathogen/microorganisms that were all found in co-infection with the bacteria (Table A4). Interestingly, in R. microplus from Guadeloupe, most of the single-infection reported corresponded to R. africae (12.9\%) or T. velifera (21.6\%) (Table A5). Positive association have been identified between T. velifera and T. mutans, and Anaplasma spp. / Borrelia spp. (Table A5). Finally, in R. microplus from Martinique, five positive associations have been detected, including $T$. mutans / T. velifera, T. mutans / Leishmania spp., T. mutans / Borrelia spp., T. velifera / B. bigemina and A. marginale/ Ehrlichia spp. (Table A6). The result of the co-occurrence test should be taken with caution and deserves further investigation regarding the few number of positive samples (Table A5, A6). Nevertheless, no exclusion seemed to occur between the pathogens/microorganisms detected in the two tick species from Guadeloupe and Martinique. More details on co-infections in ticks from Guadeloupe and Martinique are available in Appendix B.

\section{Discussion}

In this study, a high-throughput microfluidic real-time PCR system based on the use of multiple primers/probes was developed for large-scale surveys of bacteria and protozoans potentially transmitted by ticks from the Caribbean area. The association of genus and species primer/probe designs targeting TBPs improved the technology's screening capacity, enabling not only the identification of infectious agents known to circulate in the studied area, but also the detection of unsuspected TBPs and new microorganisms belonging to the main bacterial and protozoan genera/phyla involved in TBDs worldwide. Nevertheless, as some endosymbiotic microorganisms may belong to known TBP genera, such as Rickettsia and Coxiella, confirmatory tests are required before suggesting the presence of a pathogenic microorganism [23-25]. When analyzing the specificity of the microfluidic real-time PCR system, cross-reactions were observed for some designs targeting closely related species; these must be taken into account when interpreting the results. Due to high design constraints and a lack of available sequences in public databases, the improvement of such cross-reacting oligonucleotides remains challenging. Here, the concomitant use of bacterial and protozoan genera can assist in identifying non-specific signals. In addition to detecting microorganisms, we developed sets of primers and probes enabling the molecular identification of the three main tick species involved in TBDs in the Caribbean: A. variegatum, R. microplus and $R$. 
sanguineus s.l. As the morphological identification of ticks collected in the field remains challenging, molecular identification can be used to confirm the identification of the tick species analyzed $[16,26,27]$.

We used the newly developed high-throughput microfluidic real-time PCR system to perform an exploratory epidemiological study on TBPs and microorganisms potentially circulating in $A$. variegatum and R. microplus ticks collected on cattle in Guadeloupe and Martinique. The analysis provided an overview of the diversity of microorganisms belonging to the main bacterial and protozoan genera potentially transmitted by ticks. It enabled the detection both of known TBPs of public and animal health importance in the area that require surveillance and of unexpected microorganisms occurring in Caribbean ticks.

The four main pathogens responsible for ruminant diseases in the Caribbean, currently classified as notifiable diseases by the World Organization for Animal Health (OIE), have been detected by the microfluidic real-time PCR system. These are E. ruminantium in A. variegatum specimens and $A$. marginale, B. bigemina and B. bovis in R. microplus.

Interestingly, the E. ruminantium infection rate in A. variegatum reported in our study was much lower compared to in previous studies conducted between 2003 and 2005 in Guadeloupe (5.1\% versus 36.7\%) [12]. Although different study designs were used (different sampling strategies, study periods, detection methods, etc.), which may explain this difference, it would be worth further investigating whether the tick infection rate for E. ruminantium has decreased in Guadeloupe and possibly assessing the epidemiological impact in terms of the incidence and prevalence of heartwater in the ruminant population. These results are all the more surprising since systematic TBT surveillance and control programs have been discontinued in the French Antilles following the end of the POSEIDOM (Specific Options Program due to the remoteness and insularity of the overseas departments) eradication programs in 2006.

In this study, we have documented infection rates for B. bigemina, B. bovis and A. marginale in the R. microplus vector tick in the French West Indies for the first time. Indeed, records of such pathogens are mostly based on seroprevalence studies in cattle $[7,8,10]$.

R. microplus ticks are both vectors and reservoirs of B. bigemina and B. bovis, transmitting the parasites transovarially and trans-stadially $[28,29]$. As $R$. microplus ticks and cattle are both reservoirs of infection, the infection rates reported here seemed quite low. The life cycle of Babesia spp. requires complex interactions with its two hosts, which are the tick vector and the vertebrate host. The efficiency of tick acquisition and of transovarial and trans-stadial transmission of B. bovis and $B$. bigemina by R. microplus, involved in the long-term persistence of Babesia spp. in nature, is still poorly understood and warrants further investigations [28,29].

Interestingly, A. marginale was detected in R. microplus from both islands, but the infection rate reported in ticks from Guadeloupe seemed lower compared to in Martinique. The same trend had been reported during previous seroprevalence studies [7,8,10]. Anaplasmosis can be transmitted by vectors other than ticks, and some cattle breeds are known to be more susceptible than others to Anaplasma infection [10]. The difference in Anaplasma infection rate in ticks between the two islands may have been due to differences in the cattle populations. Indeed, there are mainly local Creole and mixed European-Creole breeds in Guadeloupe. These are known to be more resistant to anaplasmosis than Brahman and European breeds, which are the main breeds reared in Martinique [10]. In addition, other factors, including differences in the population dynamics of alternate vectors such as flies, may also have contributed to this difference.

Among the other known TBPs detected, we also found pathogens with low health impact in the Caribbean, almost considered as endosymbionts, such as $R$. africae, T. velifera and T. mutans in their A. variegatum vector and surprisingly in $R$. microplus ticks.

With almost all of the $A$. variegatum found to be infected, the $R$. africae infection rate was the highest ever reported in the Caribbean $[9,13,14,30]$. As A. variegatum is both the vector and the reservoir of the pathogen, with transovarial and trans-stadial transmission rates reaching $100 \%$, this high level of $R$. africae infection is not surprising per se [14,31]. Interestingly, the high $R$. africae infection rate in vector ticks, associated with a very low number of African tick-bite fever cases in the 
Caribbean, highlights the difficulty, in some cases, of clearly distinguishing between endosymbiosis and pathogenicity $[9,15]$. The biological relationship between $R$. africae and A. variegatum as well as the strain variety and virulence of $R$. africae in the Caribbean should be investigated in order to better assess risks and guide prevention measures, especially for travelers [23,24,32]. The absence of direct identification of $R$. africae in $R$. microplus ticks was probably due to lower sensitivity of the specific target design compared to the genus target design. Indeed, Rickettsia spp.-positive R. microplus samples displayed rather high $\mathrm{Ct}$ values, suggesting a low infection level that may have been below the detection limit for $R$. africae. The unusual presence of $R$. africae in $R$. microplus ticks may have been due to the co-occurrence of the two tick species, R. microplus and A. variegatum, on cattle. As the ticks here were collected partially engorged, the presence of $R$. africae in $R$. microplus may have been due to bacteria circulating in cattle blood picked up by engorging ticks, or to cross-contamination with $R$. microplus ticks co-feeding next to infected A. variegatum [33,34].

This study provides the first update on the detection of T. mutans and T. velifera in Caribbean ticks. Indeed, references to these parasites in the Caribbean are relatively old, and no prevalence studies have been conducted since, whether in ticks or in cattle $[5,6,35]$. The low pathogenicity of these piroplasms may explain the lack of diagnoses and the scarcity of information available on their distribution and prevalence in the Caribbean. However, these parasite species may play an important role in theileriosis management and protection, as chronically infected cattle can develop immunity and heterologous protection against other pathogenic Theileria species, such as Theileria parva [36]. Unfortunately, these detections still require further investigations as we did not succeed in confirming these results by conventional or nested PCR, suggesting either a level of infection below the detection threshold, or simply false signals.

Lastly, the high-throughput microfluidic real-time PCR system enabled the detection of unexpected and/or potentially new microorganisms, leading to the recovery of nucleotide sequences of Anaplasma spp., Ehrlichia spp., Borrelia spp. and Leishmania spp. in ticks collected in Guadeloupe and Martinique.

The Ehrlichia sp. Tick428 sequence detected here formed a cluster with other uncharacterized Ehrlichia species detected in ticks from Asia and Africa [13,37-41]. However, given the highly conserved nature of the 16S rRNA genes, we could not more accurately define phylogenetic relationships within the Ehrlichia species group. The Anaplasma sp. Tick314 sequence was identified as Candidatus Anaplasma boleense, a bacterium described in ticks and mosquitoes in China [40,42]. No further information is available regarding the epidemiology of Candidatus Anaplasma boleense. These observations highlight the need to set up characterization studies. Indeed, high-throughput detection technologies can highlight the presence of DNA from potentially new microorganisms, but it will still be necessary to isolate and characterize them in order to first confirm their existence and then determine whether their presence in ticks poses a risk to public or animal health.

Here we provided the first report of Borrelia spp. in ticks from Guadeloupe and Martinique. Two different sequences were recovered, according to the tick species analyzed. In A. variegatum, a sequence named Borrelia sp. Tick7 was detected and was closely related to B. anserina, the agent of avian spirochetosis. Both of them seemed to define an intermediate position between the relapsing fever and Lyme disease groups. In contrast, the Borrelia sp. Tick 457 sequence found in the R. microplus sample, clustered with uncharacterized Borrelia spp. described R. microplus specimens from Madagascar and Brazil, such as Borrelia sp. strain Mo063b and Borrelia sp. BR, and with relapsing fever Borrelia species encountered in hard ticks, including Borrelia lonestari and B. theileri [43,44]. Interestingly, the same observations had recently been made regarding Borrelia spp. found in $A$. variegatum and $R$. microplus ticks from Ethiopia and Côte d'Ivoire [45,46]. As A. variegatum and $R$. microplus were imported into the Caribbean from Africa during the time of the Atlantic triangular trade, we may have detected bacteria probably characterized by an old introduction through infected ticks and subsequent local evolution within their vector over a long period [4,47]. Borrelia spp. and borreliosis case reports in the Caribbean are scarce and still being debated. In Cuba, one study suggested the presence of antibodies to Borrelia burgdorferi sensu stricto in human sera associated with clinical cases of Lyme disease-like syndrome [48,49]. However, the real specificity of these serum 
antibodies has been questioned [50]. In the US Virgin Islands, seropositivity for Borrelia hermsii and closely related species was reported in association with a human case of relapsing fever [51]. Lastly, erythema migrans-like skin lesions and illness were reported in four Caribbean nationals [52]. Regarding the importance of Borrelia spp. for human and animal health, the characterization of these potential new Borrelia species that seemed associated with tropical tick species requires further investigation.

Lastly, Leishmania spp. were detected in R. microplus specimens from Martinique, and one sequence was identified as Leishmania martiniquensis Tick389 (accession number MK049850). Studies on Leishmania nomenclature have highlighted the fact that isolates of "L. siamensis" have never been officially characterized and that, therefore, this name should not be used [53-56]. Thus, since all the sequences, except one, reported as "L. siamensis" in databases should be considered as synonyms of L. martiniquensis, we assumed the occurrence of L. martiniquensis here. Parasites of the genus Leishmania are usually transmitted by female phlebotomine sand flies (Diptera: Psychodidae: Phlebotominae) and generally involve a wide variety of animal species, mainly including dogs and canids in the epidemiological cycle. They are responsible for leishmaniasis, a zoonosis widespread in tropical and subtropical areas [56]. L. martiniquensis belongs to the L. enriettii complex and has been described in Martinique and Thailand, where it was responsible for both cutaneous and visceral leishmaniosis [53,55-58]. L. martiniquensis is suspected to be endemic in Martinique [57]. Although phlebotomines and rodents are present in Martinique, neither vectors nor reservoirs of this parasite have yet been described [57]. Our study represents the first report of L. martiniquensis in R. microplus ticks from the French West Indies. Although Leishmania spp. have been reported in ticks (L. infantum in R. sanguineus s.l., and L. guyanensis in R. microplus ticks in Peru, for example), the role of ticks in Leishmania transmission is still being debated, and no evidence of vector capacity has been reported yet [59-61]. Moreover, the finding of Leishmania spp. in a tick species that feeds mainly on cattle also raises questions about the potential role of cattle in the epidemiology of leishmaniasis $[62,63]$. The participation of ticks in Leishmania epidemiology warrants further investigation, especially since $R$. microplus ticks could parasitize humans [64].

Surprisingly, co-infections with two or more TBPs were found in more than $50 \%$ of the infected ticks, both for A. variegatum and R. microplus and on the two islands. In addition, we could not identify any exclusion of infection between pathogens. These observations illustrate the efficiency of ticks as reservoirs of multiple pathogens with no apparent significant effects on their life traits.

To conclude, although screening tools are useful for the discovery of pathogens in ticks, the epidemiological significance of such results warrants further analysis. Detecting a microorganism's DNA in ticks, especially in partially engorged ticks removed from the host, does not necessarily mean that the ticks are the biological vector of this microorganism; however, it provides useful information to supplement vector competence studies [16]. Nevertheless, the detection of potentially new microorganisms in ticks from the French West Indies has opened up new research perspectives for the future on the epidemiology of TBPs in the Caribbean. A region-wide epidemiological survey on TBPs in ticks collected in different countries and territories of the Caribbean area, organized in collaboration with the Caribbean Animal Health Network (CaribVET) in order to strengthen our results, may be an interesting way to supplement and strengthen some of this paper's findings.

\section{Materials and Methods}

\subsection{Ticks Collected in Guadeloupe and Martinique}

The ticks used in this study were collected as part of two separate epidemiological surveys conducted in Guadeloupe (between February 2014 and January 2015) and Martinique (between February and March 2015), respectively. In Guadeloupe, adult ticks (any species, any sex) were collected from 40 cattle originating from 22 different herds that were sampled in nine localities situated in six different biotopes (urban area, dry coastal regions, valleys and hills, evergreen seasonal forest, sub-mountainous rainforest and swamp forest). In Martinique, engorged females of $R$. microplus only were collected from cattle in 29 farms participating in a study on acaricide resistance 
in ticks. All the ticks were collected from cattle with the permission of farmers and cattle owners. The ticks were morphologically identified at species level [65]. A total of 578 adult ticks were included in the study: 132 A. variegatum and 165 R. microplus ticks from Guadeloupe and 281 R. microplus ticks from Martinique (see maps, Figure 2). The GPS coordinates of the tick collection sites are available in Table S2. All the ticks were partially engorged and then stored at $-80^{\circ} \mathrm{C}$.

\subsection{DNA Extraction of Ticks Collected in Guadeloupe and Martinique}

For $20 \mathrm{mg}$ of tick, $1 \mathrm{~mL}$ of recently prepared PBS $1 \mathrm{X}$ was added to the sample. The ticks were then washed by gently shaking for 2-3 min at $7 \mathrm{~Hz} / \mathrm{s}$ in a TissueLyser (Qiagen, Hilden, Germany). After discarding the supernatant, the ticks were frozen at $-80^{\circ} \mathrm{C}$ for $15-20 \mathrm{~min}$. A steel ball was then added, and the samples were crushed twice for $2 \mathrm{~min}$ at $30 \mathrm{~Hz} / \mathrm{s}$ with the TissueLyser (Qiagen, Hilden, Germany). A total of $450 \mu \mathrm{L}$ of fresh PBS $1 \mathrm{X}$ was added to the samples. The samples were vortexed for $10 \mathrm{~s}$ and then centrifuged for 2-3 min at $8000 \mathrm{~g}$. Lastly, $20 \mu \mathrm{L}$ of Proteinase $\mathrm{K}$ was added to $150 \mu \mathrm{L}$ of crushed tick sample, and DNA was extracted using the NucleoSpin ${ }^{\circledR} 96$ Virus Core Kit (Macherey-Nagel, Düren, Germany) and the Biomek4000 automated platform (Beckman Coulter, Villepinte, France). This protocol enables the simultaneous extraction of both DNA and RNA. Total nucleic acid per sample was eluted in $160 \mu \mathrm{L}$ of rehydration solution and stored at $-80^{\circ} \mathrm{C}$ until further use. All the $A$. variegatum ticks were individually extracted, and both individual and pooled extraction have been performed on $R$. microplus ticks. Indeed, as some R. microplus specimens were too small to be treated individually ( $20 \mathrm{mg}$ of tick required), pools of two to four ticks have been carried out when required.

\subsection{Assay Design}

The list of pathogens to be monitored, the sets of primers and probes required for their detection, as well as the targeted genes are shown in Table 1. Some of the oligonucleotides were specifically designed for the purposes of this study; the others came from Michelet et al., 2014 [18]. The newly developed oligonucleotides were validated for a range of dilutions of positive controls, including cultures, plasmids and DNA samples (Table 1, Table S1), by real-time TaqMan PCR assays on a LightCycler ${ }^{\circledR} 480$ (LC480) (Roche Applied Science, Germany). More information on positive control origins are available in Table S1. Real-time PCR assays were performed with LightCycler ${ }^{\circledR} 480$ Probe Master Mix 1× (Roche Applied Science, Penzberg, Germany), using $200 \mathrm{nM}$ of primers and probes in a final volume of $12 \mu \mathrm{L}$, and $2 \mu \mathrm{L}$ of control DNA was added. The thermal cycling program was as follows: $95^{\circ} \mathrm{C}$ for $5 \mathrm{~min}, 45$ cycles at $95^{\circ} \mathrm{C}$ for $10 \mathrm{~s}$ and $60^{\circ} \mathrm{C}$ for $15 \mathrm{~s}$, and one final cooling cycle at 40 ${ }^{\circ} \mathrm{C}$ for $10 \mathrm{~s}$.

\subsection{Pre-amplification of DNA Samples}

All the DNA samples were subject to pre-amplification in order to enrich the pathogenic DNA content compared with tick DNA. PerfeCTa® PreAmp SuperMix (Quanta Biosciences, Beverly, USA) was used for DNA pre-amplification following the manufacturer's instructions. All the primers were pooled (except those targeting the tick species), with a final and equal concentration of $45 \mathrm{nM}$ each. The preamplification reaction was performed in a final volume of $5 \mu \mathrm{L}$ containing $1 \mu \mathrm{L}$ of PerfeCTa PreAmp SuperMix (5X), $1.25 \mu \mathrm{L}$ of pooled primer mix, $1.25 \mu \mathrm{L}$ of DNA and $1.5 \mu \mathrm{L}$ of Milli-Q water, with one cycle at $95^{\circ} \mathrm{C}$ for $2 \mathrm{~min}$ and 14 cycles at $95^{\circ} \mathrm{C}$ for $10 \mathrm{~s}$ and $60^{\circ} \mathrm{C}$ for $3 \mathrm{~min}$. At the end of the cycling program, the reactions were 1:10 diluted. The pre-amplified DNA were stored at $-20^{\circ} \mathrm{C}$ until use.

\subsection{High-throughput Microfluidic Real-time PCR}

High-throughput microfluidic real-time PCR amplifications were performed using the BioMark $^{\mathrm{TM}}$ real-time PCR system (Fluidigm, South San Francisco, CA, USA) and 96.96 dynamic arrays (Fluidigm, South San Francisco, CA, USA), enabling up to 9216 individual reactions to be performed in one run [18]. Real-time PCRs were performed using 6-carboxyfluorescein (6-FAM)- and Black Hole Quencher (BHQ1)-labeled TaqMan probes with TaqMan Gene Expression Master Mix 
(Applied Biosystems, Foster City, CA, USA) following the manufacturer's instructions. The cycling conditions were as follows: $2 \mathrm{~min}$ at $50{ }^{\circ} \mathrm{C}$ and $10 \mathrm{~min}$ at $95{ }^{\circ} \mathrm{C}$, followed by 40 cycles of two-step amplification for $15 \mathrm{~s}$ at $95^{\circ} \mathrm{C}$ and $1 \mathrm{~min}$ at $60^{\circ} \mathrm{C}$. The BioMark ${ }^{\mathrm{TM}}$ real-time PCR system was used for data acquisition and the Fluidigm real-time PCR analysis software for $\mathrm{Ct}$ value determination. Three kinds of controls per chip were used for experiment validation: a negative water control to exclude contamination; a DNA extraction control, corresponding to primers and probes targeting a portion of the 16S rRNA gene of ticks; and an internal control, to check the presence of PCR inhibitors made of DNA from Escherichia coli strain EDL933, added to each sample with specific primers and probes targeting the eae gene [66]. For the relative specificity analysis of the newly designed Biomark system, DNA of 62 positive controls were used as template (Table S1). Then, for the epidemiological survey of TBPs in Caribbean ticks, the 523 DNA samples of A. variegatum and R. microplus from Guadeloupe and Martinique were used as template.

\subsection{Infection Rates for Ticks from the French West Indies}

Depending on the tick species and the island of origin, for each detected pathogen, infection rates (the proportion of infected ticks divided by the total number of ticks analyzed) were calculated. The majority of the samples were single specimens of ticks. When ticks were too small to be treated individually, they were grouped into pools of two to four specimens. Thus, of the 523 samples analyzed, 47 consisted of a pool of two to four tick specimens. The final estimation of infection rates also includes the pools and is therefore expressed as the minimum (assuming at least one positive tick in the pools) and maximum (assuming all positive ticks in the pools) proportions of infected ticks out of the total number of ticks analyzed.

\subsection{PCRs and Sequencing for the Confirmation of Results}

Conventional PCRs/nested PCRs using primers targeting different genes or regions than those of the BioMark ${ }^{\mathrm{TM}}$ system were used to confirm the presence of pathogenic DNA in some field samples and positive controls (Table 3). PCR products were then sequenced by Sanger sequencing approach performed by Eurofins MWG Operon (BIOMNIS-EUROFINS GENOMICS, Nantes, France). Sequences obtained were assembled using BioEdit software (Ibis Biosciences, Carlsbad, CA, USA). An online BLAST (Basic Local Alignment Search Tool) search was used to compare the nucleotide sequences found in this study to reference sequences listed in GenBank sequence databases (NCBI).

Table 3. Primers used to confirm the presence of pathogenic DNA in tick samples.

\begin{tabular}{|c|c|c|c|c|c|}
\hline Pathogen & Targeted gene & Primername & Sequence $\left(5^{\prime} \rightarrow 3^{\prime}\right)$ & $\begin{array}{l}\text { Length } \\
\text { (bp) }\end{array}$ & References \\
\hline \multirow[t]{6}{*}{ Rickettsia spp. } & gltA & Rsfg877 & GGGGGCCTGCTCACGGCGG & 381 & [67] \\
\hline & & Rsfg1258 & ATTGCAAAAAGTACAGTGAACA & & \\
\hline & ompB & RcrompB.4362p & GTCAGCGTTACTTCTTCGATGC & 475 & [68] \\
\hline & & Rc.rompB.4836n & CСGTACTCСATCTTAGCATCAG & & \\
\hline & & RcrompB.4496p & CCAATGGCAGGACTTAGCTACT & 267 & \\
\hline & & Rc.rompB.4762n & AGGCTGGCTGATACACGGAGTAA & & \\
\hline \multirow[t]{2}{*}{ Anaplasma/Ehrlichia spp. } & 16SrRNA & EHR16SD & GGTACCYACAGAAGAAGTCC & 345 & [69] \\
\hline & & EHR16SR & TAGCACTCATCGTTTACAGC & & \\
\hline \multirow[t]{4}{*}{ Borrelia spp. } & $\mathrm{flaB}$ & $\mathrm{FlaB280F}$ & GCAGTTCARTCAGGTAACGG & 645 & [70] \\
\hline & & FlaRL & GCAATCATAGCCATTGCAGATTGT & & \\
\hline & & FlaB737F & $\begin{array}{c}\text { GCATCAACTGTRGTTGTAACATTAAC } \\
\text { AGG }\end{array}$ & 407 & \\
\hline & & FlaLL & ACATATTCAGATGCAGACAGAGGT & & \\
\hline \multirow[t]{4}{*}{ Leishmania spp. } & SSUrRNA & $\mathrm{R} 221$ & GGTTCCTTTCCTGATTTACG & 603 & [71] \\
\hline & & R332 & GGCCGGTAAAGGCCGAATAG & & \\
\hline & & $\mathrm{R} 223$ & TCCATCGCAACCTCGGTT & 358 & \\
\hline & & R333 & AAAGCGGGCGCGGTGCTG & & \\
\hline
\end{tabular}




\subsection{Phylogenetic Sequence Analysis}

Alignments were performed using ClustalW [72]. Maximum likelihood trees were generated by 1000 bootstrap repetitions based on the Tamura-Nei model [73] in MEGA7 [74]. The initial tree(s) for the heuristic search were obtained automatically by applying neighbor-joining and BioNJ algorithms to a matrix of pairwise distances estimated using the maximum composite likelihood (MCL) approach and then selecting the topology with superior log likelihood value. The tree was drawn to scale, with branch lengths measured in the number of substitutions per site. The codon positions included were $1 \mathrm{st}+2 \mathrm{nd}+3 \mathrm{rd}+$ Noncoding. All positions containing gaps and missing data were eliminated. Further information is provided in the figure legends.

\section{Conclusions}

Our study demonstrated the high ability of microfluidic real-time PCR technology to provide a rapid overview of the diversity of TBPs of veterinary and medical importance present in ticks from the Caribbean. This innovative high-throughput tool is promising and could significantly improve the surveillance and exploration of TBPs, enabling the rapid screening of multiple microorganisms especially in regions where few epidemiological data are available and TBDs are numerous.

Supplementary Materials: The following are available online at www.mdpi.com/2076-0817/9/3/176/s1, Table S1: List of the positive control samples used for the relative specificity analysis of the Biomark system developed in this study, Table S2: GPS coordinates of the tick collection sites and number of ticks collected. A total of 578 adult ticks collected from cattle from Guadeloupe and Martinique were used for the screening of tick-borne pathogens with the newly implemented BioMark ${ }^{\mathrm{TM}}$ real-time PCR system, Figure S1: Improvement of detection signals by pre-amplification. Test of primer/probe set sensitivity for a range of dilutions of positive controls by TaqMan real-time PCR using LightCycler 480, before and after pre-amplification. Results of the sensitivity test of the Leishmania infantum design using a Leishmania infantum culture, before (a) and after (c) pre-amplification; Results of the sensitivity test of the Rickettsia spp. design using Rickettsia conorii-positive controls (extracted from an infected Rhipicephalus sanguineus sensu lato tick), before (b) and after (d) pre-amplification.

Author Contributions: All authors have read and agreed to the published version of the manuscript. Conceptualization, E.A., J.P. and S.M.; methodology, M.G., E.D., V.P., R.A., C.G., S.D. and M.V.T.; formal analysis, M.G.; investigation, M.G.; writing-original draft preparation, M.G.; writing-review and editing, M.V.T., E.A., J.P. and S.M.; supervision, E.A., J.P. and S.M.; funding acquisition, M.V.T., E.A., J.P. and S.M. All authors have read and agreed to the published version of the manuscript.

Funding: This research was funded by grants from the French Agency for Food, Environmental and Occupational Health \& Safety (ANSES, Cofunding Grant no. PHD2014-2017)), the French Agricultural Research Centre for International Development (CIRAD, Cofunding Grant no. PHD2014-2017) and the French National Institute for Agricultural Research (INRAE, Grant no. PATHO-ID Metaprogram MEM 2012-2014). This study was partly supported by the MALIN project on "Surveillance, diagnosis, control and impact of infectious diseases of humans, animals and plants in tropical islands", supported by the European Union, in the framework of the European Regional Development Fund (ERDF), and the Regional Council of Guadeloupe (Grant no. 2015FED-186). The study used ticks collected in Guadeloupe and Martinique as part of previous projects: the PathoID "Rodent and tick pathobiome" project funded by INRAE and the ResisT project on "Assessment of tick resistance to acaricides in the Caribbean - Development of strategies to improve surveillance and control of tick-borne diseases in ruminants", funded by the Regional Cooperation Fund (FCR) (Grant no. FCR2013/02) of Guadeloupe and Martinique. This work was performed in the framework of EurNegVec COST Action TD1303.

Acknowledgments: We thank the "Tiques et Maladies à Tiques (TMT)" group of the CNRS "Réseau Ecologie des Interactions Durables" for stimulating discussion and support. We thank J. Pradel, M. Hamon, S. Depraz, L. Felixine, R. Aprelon and J.F. Cosson and D. Pleydell for their contribution during tick collection, and research partners that gave us control samples.

Conflicts of Interest: The authors declare no conflicts of interest. The funders had no role in the design of the study; in the collection, analyses, or interpretation of data; in the writing of the manuscript, or in the decision to publish the results. 


\section{Appendix A}

Analysis of the relative specificity of the 61 sets of primers and probe constituting the Biomark system developed in this study.

In order to identify potential cross-reactions, we analyzed the relative specificity of the 61 sets of primers and probe constituting the BioMark system used in this study using 62 positive control samples including DNA from bacterial or parasitic cultures, or DNA from tick or blood samples known to be infected, or plasmidic constructions (see Table S1).

Of the 61 designs, 42 designs were specific of their target. The Tick spp. design, used as a tick nucleic acid extraction control, was able to detect $A$. variegatum and $R$. sanguineus s.l. samples as well as the DNA of the $R$. sanguineus s.l. tick present in the Rickettsia conorii positive control as expected (Table A1). However, the DNA of ticks from the R. microplus control sample and other positive controls including tick DNA (such as the Borrelia lonestari, Anaplasma phagocytophilum controls, etc.) were not detected (Table A1). The detection ability of this design was corrected by adding the Tick spp. primers during the pre-amplification step; these had initially been excluded since the objective was to enrich pathogenic DNA content compared to tick DNA (data not shown). Eight designs displayed cross-reactions with one to two closely related species, and seven designs displayed unexpected signals corresponding likely to the detection of unexpected co-infection in complex control samples such as DNA extracted from ticks or blood samples (Table A1). Finally, three designs were removed from the system: one design due to a lack of efficiency (no detection of the target), and two designs were not specific, displaying multiple cross-reactions (Table A1).

Table A1. List of designs and their specificity using the BioMark system. CR: cross-reactions with closely related species samples; CI: potential co-infections in control samples.

\begin{tabular}{|c|c|c|c|}
\hline Design & $\begin{array}{c}\text { Target } \\
\text { Detection }\end{array}$ & Specificity & Outgroup Control Samples \\
\hline \multirow[t]{5}{*}{ Rickettsia spp.gltA } & YES & $\mathrm{CI}$ & Borrelia lonestari (Infected A. americanum ticks) \\
\hline & YES & $\mathrm{CI}$ & Ehrlichia chaffensis (Infected A. americanum ticks) \\
\hline & YES & $\mathrm{CI}$ & Ehrlichia ewingii (Infected A. americanum ticks) \\
\hline & YES & $\mathrm{CI}$ & Panola Mountain Ehrlichia (Infected A. americanum ticks) \\
\hline & YES & $\mathrm{CI}$ & Amblyommavariegatum(Wild tick) \\
\hline Rickettsia massiliae 23S-5S ITS & YES & $C R$ & Rickettsia slovaca(Culture) \\
\hline \multirow[t]{4}{*}{ Rickettsia rickettsii 23S-5S ITS } & YES & $C R^{1}$ & Rickettsia slovaca (Culture) \\
\hline & YES & & Rickettsia conorii (Infected R. sanguineus s.l. ticks) \\
\hline & YES & & Rickettsia africae(Culture) \\
\hline & YES & & Amblyomma variegatum (Wild tick) \\
\hline Rickettsia conorii sca1 & YES & $C R$ & Rickettsia slovaca(Culture) \\
\hline Rickettsia africae sca1 & YES & $\mathrm{CI}$ & Amblyommavariegatum (Wild tick) \\
\hline \multirow[t]{4}{*}{ Rickettsia felis orfB } & YES & $\mathrm{CI}$ & Borrelia lonestari (Infected A. americanum ticks) \\
\hline & YES & $\mathrm{CI}$ & Ehrlichia chaffensis (Infected A. americanum ticks) \\
\hline & YES & $\mathrm{CI}$ & Ehrlichia ewingii (Infected A. americanum ticks) \\
\hline & YES & $\mathrm{CI}$ & Panola Mountain Ehrlichia (Infected A. americanum ticks) \\
\hline Rickettsia typhiompB & YES & YES & \\
\hline Rickettsia prowazekii gltA & YES & YES & \\
\hline Borrelia spp. $23 S r R N A$ & YES & YES & \\
\hline $\begin{array}{c}\text { Borrelia burgdorferi sensu stricto } \\
\qquad g h A\end{array}$ & $\mathrm{NO}^{1}$ & & \\
\hline Borrelia anserina fla & YES & YES & \\
\hline Borrelia lonestariglpQ & YES & YES & \\
\hline Borrelia parkerigyrB & YES & YES & \\
\hline Borreliabissettii rpoB & YES & YES & \\
\hline Borrelia theileriglpQ & YES & YES & \\
\hline
\end{tabular}




\begin{tabular}{|c|c|c|c|}
\hline Bartonella spp.ssrA & YES & YES & \\
\hline Bartonella baciliformis rpoB & YES & $C R$ & Bartonella henselae (Culture) \\
\hline Bartonellahenselae ribC & YES & $C R$ & Bartonella bacilliformis (Culture) \\
\hline $\begin{array}{c}\text { Bartonella vinsonii subsp. } \\
\text { berkhoffii ITS }\end{array}$ & YES & YES & \\
\hline Coxiellaburnetiiicd & YES & YES & \\
\hline Coxiellaburnetii IS 1111 & YES & YES & \\
\hline Francisella tularensis tul4 & YES & YES & \\
\hline Francisella tularensis fopA & YES & YES & \\
\hline Anaplasma spp. 16SrRNA & YES & YES & \\
\hline Anaplasma marginalemsp1b & YES & YES & \\
\hline $\begin{array}{l}\text { Anaplasma phagocytophilum } \\
\text { msp2 }\end{array}$ & YES & YES & \\
\hline Anaplasma platys groEL & YES & YES & \\
\hline Anaplasma bovis groEL & YES & YES & \\
\hline Anaplasma ovis msp4 & YES & YES & \\
\hline Ehrlichia spp. 16S rRNA & YES & YES & \\
\hline Ehrlichia canis glt $A$ & YES & YES & \\
\hline Ehrlichia chaffeensis dsb & YES & YES & \\
\hline Ehrlichia ewingiidsb & YES & YES & \\
\hline Ehrlichia ruminantium gltA & YES & YES & \\
\hline $\begin{array}{l}\text { Panola Mountain Ehrlichia } \\
\text { gltA }\end{array}$ & YES & YES & \\
\hline Neoehrlichia mikurensis groEL & YES & YES & \\
\hline Aegyptianella pullorum groEL & YES & YES & \\
\hline \multirow[t]{5}{*}{ Apicomplexa 18SrRNA } & YES & $\mathrm{CI}$ & Borrelia lonestari (Infected A. americanum ticks) \\
\hline & YES & $\mathrm{CI}$ & Anaplasma marginale (Infected cow blood) \\
\hline & YES & CI & Panola Mountain Ehrlichia (Infected A. americamum ticks) \\
\hline & YES & CI & Neoehrlichia mikurensis (Infected rodent blood) \\
\hline & YES & $\mathrm{CI}$ & Rhipicephalus sanguineus s.l.(Wild tick) \\
\hline Babesia canis vogeli hsp70 & YES & $C R$ & Babesia canis canis (Infected dog blood) \\
\hline \multirow[t]{17}{*}{ Babesia ovis 18S rRNA } & YES & $C R^{1}$ & Rickettsia massiliae(Culture) \\
\hline & YES & & Borrelia lonestari (Infected A. americanum ticks) \\
\hline & YES & & Anaplasma marginale (Infected cow blood) \\
\hline & YES & & Ehrlichia chaffensis (Infected A. americanum ticks) \\
\hline & YES & & Ehrlichia ewinguï(Infected A. americanum ticks) \\
\hline & YES & & Panola Mountain Ehrlichia (Infected A. americanum ticks) \\
\hline & YES & & Neoehrlichia mikurensis (Infected rodent blood) \\
\hline & YES & & Babesia divergens(Culture) \\
\hline & YES & & Babesia canis rossi (Infected dog blood) \\
\hline & YES & & Babesia canis canis (Infected dog blood) \\
\hline & YES & & Babesia canis vogeli (Infected dog blood) \\
\hline & YES & & Babesiamicroti (Culture) \\
\hline & YES & & Theileria annulata (Culture) \\
\hline & YES & & Theileria lestoquardi(Culture) \\
\hline & YES & & Theileria parva (Culture) \\
\hline & YES & & Hepatozoon canis (Infected dog blood) \\
\hline & YES & & Rhipicephalus sanguineus s.l.(Wild tick) \\
\hline Babesia bigemina 18S rRNA & YES & CI & Anaplasma marginale (Infected cow blood) \\
\hline Babesia gibsoni Rap1 & YES & YES & \\
\hline Babesia caballi Rap1 & YES & YES & \\
\hline
\end{tabular}




\begin{tabular}{|c|c|c|c|}
\hline Babesia bovis CCTeta & YES & YES & \\
\hline Babesia duncani ITS2 & YES & YES & \\
\hline Babesia microtiCCTeta & YES & $C R$ & Babesia canis canis (Infected dog blood) \\
\hline \multirow[t]{2}{*}{ Theileria parva $18 S \mathrm{r} R N A$} & YES & $C R$ & Theileria annulata (Culture) \\
\hline & YES & $C R$ & Theileria lestoquardi(Culture) \\
\hline Theileria mutans ITS & YES & YES & \\
\hline Theileria velifera 18S $r R N A$ & YES & YES & \\
\hline Theileria equiema1 & YES & YES & \\
\hline Cytauxzoon felis ITS2 & YES & YES & \\
\hline \multirow[t]{2}{*}{ Hepatozoon spp 18S rRNA } & YES & $\mathrm{Cl}$ & Neoehrlichia mikurensis (Infected rodent blood) \\
\hline & YES & $\mathrm{CI}$ & Rhipicephalus sanguineus s.l.(Wild tick) \\
\hline Hepatozoon canis $18 S$ rRNA & YES & $\mathrm{CI}$ & Rhipicephalus sanguineus s.l.(Wild tick) \\
\hline \multirow[t]{2}{*}{$\begin{array}{c}\text { Hepatozoon americanum } 18 S \\
r R N A \\
\end{array}$} & YES & $\mathrm{CR}$ & Hepatozoon canis (Infected dog blood) \\
\hline & YES & $\mathrm{CI}$ & Rhipicephalus sanguineus s.l.(Wild tick) \\
\hline Leishmania spp hsp70 & YES & YES & \\
\hline Leishmania infantum ITS & YES & YES & \\
\hline Rangelia vitalii $18 S$ rRNA & YES & YES & \\
\hline Tickspp.16SrRNA & YES & $Y E S^{2}$ & \\
\hline Amblyomma variegatum ITS2 & YES & YES & \\
\hline Rhipicephalus microplus ITS2 & YES & YES & \\
\hline $\begin{array}{l}\text { Rhipicephalus sanguineus s.l. } \\
\text { ITS2 }\end{array}$ & YES & YES & \\
\hline
\end{tabular}

${ }^{1}$ Designs removed from the screening analysis. ${ }^{2}$ Tick spp. primers required to be part of the preamplification mix in order to achieve correct detection signals.

Regarding the seven designs displaying unexpected signals, we decided to explore the hypothesis of potential co-infection in controls corresponding to DNA from ticks or blood samples using conventional PCR and amplicon sequencing (Table A1).

Both the Rickettsia spp. and Rickettsia felis designs gave positive results when testing the Borrelia lonestari, Panola Mountain Ehrlichia, Ehrlichia ewingii and Ehrlichia chaffensis controls. All these samples corresponded to DNA extracted from infected Amblyomma americanum collected in the field (USA). This result supports the fact that a Rickettsia species may have been present in these samples, whether it was Rickettsia felis or a closely related Rickettsia spp. infecting Amblyomma americanum ticks. When testing the Panola Mountain Ehrlichia sample for Rickettsia spp. by conventional PCR targeting the gltA gene [67], we obtained a 382 bp sequence (accession number MK049843) sharing 99\% sequence identity with Rickettsia spp. (MF511253.1) (Table A2). This result, in addition to natural coinfections documented in Amblyomma americanum ticks, suggest that the detection of Rickettsia spp., within the four outgroup positive controls corresponding to Amblyomma americanum DNA, in this assay did not correspond to cross-reactions [75,76]. Moreover, the Amblyomma variegatum sample, corresponding to ticks collected from the field, was found to be positive for both Rickettsia spp. and Rickettsia africae. As this sample originated from Guadeloupe, where Rickettsia africae circulates, this result may have been in agreement with a natural infection [9]. 
Table A2. Taxonomic assignment of the sequences obtained after sequencing PCR products to confirm the presence of co-infections in complex control samples corresponding to DNA extracted from wild ticks or blood samples. AN: accession number, \% I: percentage identity, \% C: percentage coverage.

\begin{tabular}{|c|c|c|c|c|c|c|c|}
\hline Tested Control Sample & Tested for & AN & $\begin{array}{c}\text { Length } \\
\text { (bp) }\end{array}$ & Closest Homology & $\% \mathbf{I}$ & $\% \mathrm{C}$ & AN \\
\hline $\begin{array}{c}\text { Panola Mountain Ehrlichia } \\
\text { (Infected A. americanum } \\
\text { ticks) }\end{array}$ & Rickettsiaspp. & MK049843 & 382 & Rickettsia spp. & 99 & 100 & MF511253.1 \\
\hline $\begin{array}{l}\text { Neoehrlichia mikurensis } \\
\text { (Infected rodentblood) }\end{array}$ & $\begin{array}{l}\text { Hepatozoon } \\
\text { spp. }\end{array}$ & MK071735 & 169 & Hepatozoon spp. & 99 & 100 & AB771515.1 \\
\hline $\begin{array}{l}\text { Anaplasma marginale } \\
\text { (Infected cow blood) }\end{array}$ & Apicomplexa & MK071737 & 104 & $\begin{array}{l}\text { Babesia spp., Theileria spp. } \\
\text { (including B. bigemina) }\end{array}$ & 100 & 99 & MG604302.1 \\
\hline $\begin{array}{c}\text { Panola Mountain Ehrlichia } \\
\text { (Infected A. americanum } \\
\text { ticks) }\end{array}$ & Apicompl & -MK071736 & 102 & Theileria spp. & 98 & 100 & ИH085203.1 \\
\hline $\begin{array}{c}\text { Borrelia lonestari } \\
\text { (Infected A. americanum } \\
\text { ticks) }\end{array}$ & Apicomplexa & $-I V I N U / 1 / 30$ & 102 & (including T.cervi) & 90 & 100 & 111003200.1 \\
\hline
\end{tabular}

Moreover, the Rhipicephalus sanguineus s.l. sample was positive with four designs targeting parasites: Apicomplexa, Hepatozoon spp., Hepatozoon canis and Hepatozoon americanum. Since Rhipicephalus sanguineus s.l. ticks are involved in the epidemiology of tick-borne parasites including Hepatozoon spp., these results strongly suggest the occurrence of such parasites in the biological sample [77]. Thus, these observations suggest that our designs were actually capable of detecting pathogens present in naturally infected ticks rather than giving an unsuspected cross-reaction. The Neoehrlichia mikurensis sample, corresponding to DNA extracted from rodent blood, was also found to be positive for both Apicomplexa and Hepatozoon spp. The amplicon obtained from this sample with the Hepatozoon spp. design was sequenced. The obtained 169 bp sequence (accession number MK071735) displayed 99\% sequence identity with the Hepatozoon spp. sequences (AB771515.1) (Table A2). As rodents can be infected with Hepatozoon parasites, this result could also reflect a natural infection [78]. The Anaplasma marginale sample, corresponding to a blood sample from an experimentally infected cow, was also found to be positive for both Apicomplexa and Babesia bigemina. The amplicon obtained from this sample with the Apicomplexa design was sequenced. The obtained $104 \mathrm{bp}$ sequence (accession number MK071737) displayed 99\% sequence identity with the Apicomplexan sequences, including Babesia bigemina (MG604302.1) (Table A2). As Babesia bigemina and Anaplasma marginale are two cattle pathogens that have often evolved in the same region and are transmitted by the same vector tick, co-infections with these two pathogens have already been reported [79]. Thus, this cross-reaction may again have been a reflection of parasite co-infections. Lastly, Apicomplexa also gave positive results in the Borrelia lonestari and Panola Mountain Ehrlichia controls. As highlighted previously, these two controls corresponded to DNA extracted from $A$. americanum ticks. The amplicons obtained from these two samples with the Apicomplexa design were sequenced. The two obtained $102 \mathrm{bp}$ sequences (accession number MK071736) were identical and displayed 98\% sequence identity with the Theileria cervi sequences (MH085203.1) (Table A2). As Theileria cervi is a common deer pathogen found in Amblyomma americanum, the occurrence of this parasite in these two control samples could explain the unexpected signals [80,81].

\section{Appendix B}

Analysis of the co-infections detected in Amblyomma variegatum and Rhipicephalus microplus ticks collected in Guadeloupe and Martinique.

Here we reported the co-infections observed in Amblyomma variegatum ( $\mathrm{n}=132$ samples), Rhipicephalus microplus collected in Guadeloupe $(\mathrm{n}=116$ samples, including individual and pooled 
specimens) and Martinique ( $\mathrm{n}=275$ samples, including individual and pooled specimens) (Table A3). We combined the results obtained with the Rickettsia spp. and the $R$. africae design, assuming that only R. africae have been detected in the Caribbean samples analyzed here. In addition, Anaplasma spp. results here correspond to samples only positive for Anaplasma spp. and not for A. marginale, as well, Ehrlichia spp. results here correspond to samples only positive for Ehrlichia spp. and not for E. ruminantium.

Table A3. Co-infection analysis in A. variegatum ( $\mathrm{n}=132$ samples) and $R$. microplus collected in Guadeloupe ( $\mathrm{n}=116$ samples) and Martinique $(\mathrm{n}=275$ samples).

\begin{tabular}{|c|c|c|c|}
\hline & $\begin{array}{l}\text { A. variegatum Sample } \\
\text { (Percentage) }\end{array}$ & $\begin{array}{l}\text { R. microplus Sample from } \\
\text { Guadeloupe (Percentage) }\end{array}$ & $\begin{array}{l}\text { R. microplus Sample } \\
\text { from Martinique } \\
\text { (Percentage) }\end{array}$ \\
\hline Total of sample & 132 & 116 & 275 \\
\hline Total of non-infected sample & $1(0.8)$ & $51(44)$ & $52(19)$ \\
\hline $\begin{array}{c}\text { Total of } \\
\text { infected sample }\end{array}$ & $131(99.2)$ & $65(56)$ & $223(81)$ \\
\hline Singleinfections & $69(52.3)$ & $47(40.5)$ & $99(36)$ \\
\hline R. africae ${ }^{1}$ & $68(51.5)$ & $15(12.9)$ & 0 \\
\hline Anaplasma spp. ${ }^{2}$ & & $1(0.9)$ & $10(3.6)$ \\
\hline A. marginale & 0 & $2(1.7)$ & $22(8)$ \\
\hline Ehrlichia spp. ${ }^{3}$ & 0 & $3(2.6)$ & $43(15.6)$ \\
\hline Borrelia spp. & 0 & 0 & $3(1.1)$ \\
\hline B. bigemina & 0 & $1(0.9)$ & $7(2.5)$ \\
\hline T.velifera & $1(0.8)$ & $25(21.6)$ & $14(5.1)$ \\
\hline Co-infections (2) & $53(40.2)$ & $16(13.8)$ & $88(32)$ \\
\hline R. africae $1 /$ T.velifera & $47(35.6)$ & $6(5.2)$ & 0 \\
\hline R. africae ${ }^{1 /}$ Borrelia spp. & $3(2.3)$ & 0 & 0 \\
\hline R. africae ${ }^{1 /}$ E. ruminantium & $3(2.3)$ & 0 & 0 \\
\hline Anaplasma spp. 2/ Borrelia spp. & 0 & $1(0.9)$ & 0 \\
\hline Anaplasma spp. ${ }^{2 /}$ T.velifera & 0 & $2(1.7)$ & $3(1.1)$ \\
\hline Anaplasma spp. ${ }^{2 /}$ Ehrlichia spp. ${ }^{3}$ & 0 & 0 & $6(2.2)$ \\
\hline A. marginale / T.velifera & 0 & $2(1.7)$ & $10(3.6)$ \\
\hline A. marginale / Borrelia spp. & 0 & 0 & $3(1.1)$ \\
\hline A. marginale / Ehrlichia spp. ${ }^{3}$ & 0 & 0 & $39(14.29)$ \\
\hline A. marginale / B. bigemina & 0 & 0 & $4(1.5)$ \\
\hline Ehrlichia spp. ${ }^{3} /$ R. africae ${ }^{1}$ & 0 & $2(1.7)$ & 0 \\
\hline Ehrlichia spp. ${ }^{3} /$ T. velifera & 0 & $1(0.9)$ & $8(2.9)$ \\
\hline Ehrlichia spp. ${ }^{3}$ / Borrelia spp. & 0 & 0 & $3(1.1)$ \\
\hline Ehrlichia spp. ${ }^{3} /$ Leishmania spp. & 0 & 0 & $1(0.4)$ \\
\hline T. velifera / B. bigemina & 0 & 0 & $10(3.6)$ \\
\hline T.velifera/T.mutans & 0 & $2(1.7)$ & $1(0.4)$ \\
\hline Co-infections (3) & $8(6.1)$ & $2(1.7)$ & $26(9.5)$ \\
\hline R.africae ${ }^{1 / \text { E. ruminantium / T. velifera }}$ & $3(2.3)$ & 0 & 0 \\
\hline R. africae ${ }^{1 /}$ Borrelia spp. / T. velifera & $3(2.3)$ & 0 & 0 \\
\hline R. africae $1 /$ T.velifera / T. mutans & $2(1.5)$ & $1(0.6)$ & 0 \\
\hline $\begin{array}{l}\text { R. africae } 1 / \text { A. marginale / Ehrlichia } \\
\text { spp. }{ }^{3}\end{array}$ & 0 & $1(0.6)$ & 0 \\
\hline $\begin{array}{l}\text { A. marginale/Ehrlichia spp. }{ }^{3 / B} \text {. } \\
\text { bigemina }\end{array}$ & 0 & 0 & $8(2.9)$ \\
\hline A. marginale / Ehrlichia spp. $3 /$ B.boris & 0 & 0 & $1(0.4)$ \\
\hline
\end{tabular}




\begin{tabular}{|c|c|c|c|c|}
\hline & $\begin{array}{l}\text { A. marginale / Ehrlichia spp. } 3 / \mathrm{T} \text {. } \\
\text { velifera }\end{array}$ & 0 & 0 & $15(5.5)$ \\
\hline & $\begin{array}{c}\text { Anaplasma spp. }{ }^{2 / E h r l i c h i a ~ s p p .}{ }^{3} / B . \\
\text { bigemina }\end{array}$ & 0 & 0 & $1(0.4)$ \\
\hline & $\begin{array}{c}\text { Anaplasma spp. } 2 / \text { Ehrlichia spp. }{ }^{3 /} \\
\text { T.velifera }\end{array}$ & 0 & 0 & $1(0.4)$ \\
\hline \multirow{7}{*}{ Co-infections (4) } & Total & $1(0.8)$ & 0 & $9(3.3)$ \\
\hline & $\begin{array}{c}\text { R. africae } 1 \text { / T. velifera / Borrelia spp./ } \\
\text { E. ruminantium }\end{array}$ & $1(0.8)$ & 0 & 0 \\
\hline & $\begin{array}{c}\text { A. marginale / Borrelia spp. / T. velifera } \\
\text { / } \\
\text { T.mutans } \\
\end{array}$ & 0 & 0 & $1(0.4)$ \\
\hline & $\begin{array}{c}\text { A. marginale / Ehrlichia spp. } 3 / T \text {. } \\
\text { velifera/ } \\
\text { B. bigemina }\end{array}$ & 0 & 0 & $5(1.8)$ \\
\hline & $\begin{array}{l}\text { A. marginale / Ehrlichia spp. }{ }^{3} \text { / T. } \\
\text { velifera / B.bovis }\end{array}$ & 0 & 0 & $1(0.4)$ \\
\hline & $\begin{array}{l}\text { A. marginale / Leishmania spp./T. } \\
\text { velifera/ } \\
\text { T.mutans } \\
\end{array}$ & 0 & 0 & $1(0.4)$ \\
\hline & $\begin{array}{c}\text { Anaplasma spp. } 2 / \text { Ehrlichia spp. } 3 / \\
\text { Borrelia spp./ } \\
\text { T. velifera }\end{array}$ & 0 & 0 & $1(0.4)$ \\
\hline \multirow[t]{2}{*}{ Co-infections (5) } & Total & 0 & 0 & $1(0.4)$ \\
\hline & $\begin{array}{c}\text { A. marginale / Ehrlichia spp. }{ }^{3 /} \\
\text { Borrelia spp./ } \\
\text { T. velifera / T. mutans }\end{array}$ & 0 & 0 & $1(0.4)$ \\
\hline
\end{tabular}

${ }^{1}$ Assuming that all the Rickettsia spp. found in Rhipicephalus microplus samples from Guadeloupe were R. africae. ${ }^{2}$ Sample positive for Anaplasma spp. and not for A. marginale. ${ }^{3}$ Sample positive for Ehrlichia spp. and not for E. ruminantium.

Almost all of the A. variegatum samples from Guadeloupe were infected with at least one microorganism (99.2) (Table A3). Interestingly, only 56 of the $R$. microplus samples from Guadeloupe were infected with at least one microorganism, whereas this rate reached 81 of the R. microplus from Martinique (Table A3). Most of the positive samples corresponded to single infection or co-infection with two microorganisms in both tick species. Then, less than 10 of the tick samples displayed coinfections with three microorganisms (Table A3). Finally, only one A. variegatum sample from Guadeloupe and nine $R$. microplus samples from Martinique were co-infected with four microorganisms, and one R. microplus from Martinique was found infected with five microorganisms (Table A3).

The majority of the A. variegatum samples displayed single infections with $R$. africae (52) or coinfections with $R$. africae and T. velifera (36) (Table A3). Nevertheless, no negative or positive associations have been detected between the microorganisms detected in $A$. variegatum samples (Table A4). At least, the presence of $R$. africae do not seem to interfere with the presence of T. velifera (Table A4). 
Table A4. Co-occurrence matrix of the microorganisms detected in A. variegatum samples collected in Guadeloupe ( $\mathrm{n}=132$ samples). No negative or positive association have been detected when performing a co-occurrence test using the co-occur function $(\alpha=0.05)$ and $\mathrm{R}$ version 3.6.0 (2019-0426).

\begin{tabular}{cccccc}
\hline & E. ruminantium & Borrelia spp. & R. africae & T. mutans & T. velifera \\
\hline E. ruminantium & 7 & $\mathbf{1}$ & 7 & $\mathbf{0}$ & $\mathbf{4}$ \\
\hline Borrelia spp. & 7 & 7 & $\mathbf{0}$ & $\mathbf{4}$ \\
\hline R. africae & & 130 & $\mathbf{2}$ & $\mathbf{5 6}$ \\
\hline T. mutans & & & 2 & $\mathbf{2}$ \\
\hline T. velifera & & & & 57 \\
\hline
\end{tabular}

Among the 116 R. microplus samples from Guadeloupe analyzed here, most of the positive samples presented single-infection (40.5), with R. africae (12.9) or T. velifera (21.6) (Table A3). As $R$. microplus is not considered as a vector of both of these microorganisms, we made the hypothesis of a possible contamination of this tick species via infected bovine blood still present in engorged tick, and/or via co-feeding with infected A. variegatum ticks. Interestingly, if we remove $R$. africae, T. velifera and T. mutans from the screening analysis, the percentage of infected R. microplus from Guadeloupe dropped drastically to $13.8 \%$ (16/116 samples infected with at least one microorganism). This observation is particularly surprising when comparing this rate to the 81 infected $R$. microplus from Martinique (see below). When testing for co-occurrence linkage, two positive associations have been detected between the microorganisms detected in R. microplus samples from Guadeloupe, including T. velifera / T. mutans and Anaplasma spp. / Borrelia spp. (Table A5). Co-infections and positive associations between T. velifera and T. mutans have already been reported in the literature, such as in cattle sera from Uganda and Kenya [82,83]. Regarding the few samples positive for Anaplasma spp. and Borrelia spp., the result of the co-occurrence test should be taken with caution and deserves further investigation. Nevertheless, no exclusion seemed to occur between the microorganisms detected in R. microplus from Guadeloupe (Table A5).

Table A5. Co-occurrence matrix of the microorganisms detected in R. microplus samples collected in Guadeloupe ( $\mathrm{n}=116$ samples). *: Positive association detected when performing a co-occurrence test using the co-occur function $(\alpha=0.05)$ and $\mathrm{R}$ version 3.6.0 (2019-04-26).

\begin{tabular}{|c|c|c|c|c|c|c|c|c|}
\hline & $\begin{array}{c}A . \\
\text { marginale } \\
\end{array}$ & $\begin{array}{l}\text { Borrelia } \\
\text { spp. }\end{array}$ & R. africae & T. mutans & T. velifera $B$ & B. bigemina & Anaplasma spp. ${ }^{1}$ & $\begin{array}{c}\text { Ehrlichia } \\
\text { spp. }{ }^{2}\end{array}$ \\
\hline A. marginale & 5 & 0 & 1 & 0 & 2 & 0 & 0 & 1 \\
\hline Borrelia spp. & & 1 & 0 & 0 & 0 & 0 & $1^{*}$ & 0 \\
\hline R. africae & & & 25 & 1 & 7 & 0 & 0 & 3 \\
\hline T. mutans & & & & 3 & $3^{*}$ & 0 & 0 & 0 \\
\hline T. velifera & & & & & 39 & 0 & 2 & 1 \\
\hline B. bigemina & & & & & & 1 & 0 & 0 \\
\hline $\begin{array}{l}\text { Anaplasma } \\
\text { spp. }{ }^{1}\end{array}$ & & & & & & & 4 & 0 \\
\hline Ehrlichia spp. ${ }^{2}$ & & & & & & & & 7 \\
\hline
\end{tabular}

${ }^{1}$ Sample positive for Anaplasma spp. and not for A. marginale. ${ }^{2}$ Sample positive for Ehrlichia spp. and not for E. ruminantium.

Among the 275 R. microplus samples from Guadeloupe, most of the samples presented singleinfection (36) and co-infections with two microorganisms (32) (Table A1). Five positive associations have been detected between the microorganisms detected in $R$. microplus samples from Martinique (Table A6). T. mutans have been found in positive association with T. velifera, as previously observed in the same tick species from Guadeloupe, and with Leishmania spp. and Borrelia spp. In addition, $T$. velifera were found in positive association with B. bigemina and Ehrlichia spp. with A. marginale. Finally, no negative associations have been reported between the microorganisms detected in $R$. microplus from Martinique (Table A6). 
Table A6. Co-occurrence matrix of the microorganisms detected in R. microplus samples collected in Martinique ( $\mathrm{n}=275$ samples). ${ }^{*}$ ) Positive associations detected when performing a co-occurrence test using the co-occur function $(\alpha=0.05)$ and $\mathrm{R}$ version 3.6.0 (2019-04-26).

\begin{tabular}{|c|c|c|c|c|c|c|c|c|c|}
\hline & $\begin{array}{c}A . \\
\text { marginale }\end{array}$ & $\begin{array}{c}\text { Borrelia } \\
\text { spp. }\end{array}$ & $\begin{array}{l}\text { Leishmania } \\
\text { spp. }\end{array}$ & T.mutans & T.velifera & B. bigemina & B.bovis & $\begin{array}{c}\text { Anaplasma } \\
\text { spp. }^{1}\end{array}$ & $\begin{array}{c}\text { Ehrlichia } \\
\text { spp. }^{2}\end{array}$ \\
\hline A. marginale & 111 & 5 & 1 & 3 & 34 & 17 & 2 & 0 & $70^{*}$ \\
\hline Borrelia spp. & & 12 & 0 & $2^{*}$ & 3 & 0 & 0 & 1 & 5 \\
\hline $\begin{array}{l}\text { Leishmania } \\
\text { spp. }\end{array}$ & & & 2 & $1^{*}$ & 1 & 0 & 0 & 0 & 1 \\
\hline T.mutans & & & & 4 & $4^{*}$ & 0 & 0 & 0 & 1 \\
\hline T.velifera & & & & & 72 & $15^{*}$ & 1 & 5 & 32 \\
\hline B. bigemina & & & & & & 35 & 0 & 1 & 14 \\
\hline B.bovis & & & & & & & 2 & 0 & 2 \\
\hline $\begin{array}{c}\text { Anaplasma } \\
\text { spp. }^{1}\end{array}$ & & & & & & & & 22 & 9 \\
\hline $\begin{array}{c}\text { Ehrlichia } \\
\text { spp. }\end{array}$ & & & & & & & & & 134 \\
\hline
\end{tabular}

${ }^{1}$ Sample positive for Anaplasma spp. and not for A. marginale. ${ }^{2}$ Sample positive for Ehrlichia spp. and not for E. ruminantium.

\section{References}

1. Dantas-Torres, F.; Chomel, B.B.; Otranto, D. Ticks and tick-borne diseases: a One Health perspective. Trends Parasitol. 2012, 28, 437-446. doi: 10.1016/j.pt.2012.07.003

2. George, J.E.; Davey, R.B.; Pound, J.M. Introduced ticks and tick-borne diseases: the threat and approaches to eradication. Vet. Clin. North Am. Food Anim. Pract. 2002, 18, 401-416, vi.

3. Gondard, M.; Cabezas-Cruz, A.; Charles, R.A.; Vayssier-Taussat, M.; Albina, E.; Moutailler, S. Ticks and Tick-Borne Pathogens of the Caribbean: Current Understanding and Future Directions for More Comprehensive Surveillance. Front Cell Infect Microbiol 2017, 7, 490. doi:10.3389/fcimb.2017.00490.

4. Barré, N.; Uilenberg, G. Spread of parasites transported with their hosts: case study of two species of cattle tick. Rev. - Off. Int. Epizoot. 2010, 29, 149-160, 135-147.

5. Morel, P.-C. Etudes sur les tiques du bétail en Guadeloupe et Martinique. II. Agents pathogènes transmis par les tiques. Revue d'élevage et de médecine vétérinaire des pays tropicaux 1967, 20, $291-299$. Doi:10.19182/remvt.7508.

6. Uilenberg, G.; Camus, E.; Barré, N. [Existence of Theileria mutans and Theileria velifera (Sporozoa, Theileriidae) in Guadeloupe (French West Indies)]. Rev Elev Med Vet Pays Trop 1983, 36, 261-264.

7. Camus, E.; Barre, N. Vector situation of tick-borne diseases in the Caribbean islands. Vet. Parasitol. 1995, 57, 167-176. Doi: 10.1016/0304-4017(94)03118-G.

8. Alonso, M.; Arellano-Sota, C.; Cereser, V.H.; Cordoves, C.O.; Guglielmone, A.A.; Kessler, R.; Mangold, A.J.; Nari, A.; Patarroyo, J.H.; Solari, M.A. Epidemiology of bovine anaplasmosis and babesiosis in Latin America and the Caribbean. Rev. Sci. Tech. 1992, 11, 713-733.

9. Parola, P.; Vestris, G.; Martinez, D.; Brochier, B.; Roux, V.; Raoult, D. Tick-borne rickettiosis in Guadeloupe, the French West Indies: isolation of Rickettsia africae from Amblyomma variegatum ticks and serosurvey in humans, cattle, and goats. Am. J. Trop. Med. Hyg. 1999, 60, 888-893.

10. Camus, E.; Montenegro-James, S. Bovine anaplasmosis and babesiosis in the Lesser Antilles: risk assessment of an unstable epidemiologic situation. Vet. Res. 1994, 25, 313-317.

11. Barre, N.; Garris, G.I.; Borel, G.; Camus, E. Hosts and Population Dynamics of Amblyomma variegatum (Acari: Ixodidae) on Guadeloupe, French West Indies. J Med Entomol 1988, 25, 111-115. doi: 10.1093/jmedent/25.2.111.

12. Vachiéry, N.; Jeffery, H.; Pegram, R.; Aprelon, R.; Pinarello, V.; Kandassamy, R.L.Y.; Raliniaina, M.; Molia, S.; Savage, H.; Alexander, R.; et al. Amblyomma variegatum ticks and heartwater on three Caribbean Islands. Ann. N. Y. Acad. Sci. 2008, 1149, 191-195. doi: 10.1196/annals.1428.081.

13. Parola, P.; Attali, J.; Raoult, D. First detection of Rickettsia africae on Martinique, in the French West Indies. Ann Trop Med Parasitol 2003, 97, 535-537. doi: 10.1179/000349803225001382. 
14. Kelly, P.; Lucas, H.; Beati, L.; Yowell, C.; Mahan, S.; Dame, J. Rickettsia africae in Amblyomma variegatum and domestic ruminants on eight Caribbean islands. J. Parasitol. 2010, 96, 1086-1088. doi: 10.1645/GE-2552.1.

15. Raoult, D.; Fournier, P.E.; Fenollar, F.; Jensenius, M.; Prioe, T.; de Pina, J.J.; Caruso, G.; Jones, N.; Laferl, H.; Rosenblatt, J.E.; et al. Rickettsia africae, a Tick-Borne Pathogen in Travelers to Sub-Saharan Africa. New Engl. J. Med. 2001, 344, 1504-1510. doi: 10.1056/NEJM200105173442003.

16. Estrada-Peña, A.; Gray, J.S.; Kahl, O.; Lane, R.S.; Nijhof, A.M. Research on the ecology of ticks and tickborne pathogens-methodological principles and caveats. Front Cell Infect Microbiol 2013, 3, 29. doi: 10.3389/fcimb.2013.00029.

17. Cabezas-Cruz, A.; Vayssier-Taussat, M.; Greub, G. Tick-borne pathogen detection: what's new? Microbes Infect. 2018. 20, 441-444. doi: 10.1016/j.micinf.2017.12.015.

18. Michelet, L.; Delannoy, S.; Devillers, E.; Umhang, G.; Aspan, A.; Juremalm, M.; Chirico, J.; van der Wal, F.J.; Sprong, H.; Boye Pihl, T.P.; et al. High-throughput screening of tick-borne pathogens in Europe. Front Cell Infect Microbiol 2014, 4. doi: 10.3389/fcimb.2014.00103.

19. Dupraz, M.; Toty, C.; Devillers, E.; Blanchon, T.; Elguero, E.; Vittecoq, M.; Moutailler, S.; McCoy, K.D. Population structure of the soft tick Ornithodoros maritimus and its associated infectious agents within a colony of its seabird host Larus michahellis. Int J Parasitol Parasites Wildl 2017, 6, 122-130. doi: 10.1016/j.jppaw.2017.05.001.

20. Gioia, G.V.; Vinueza, R.L.; Marsot, M.; Devillers, E.; Cruz, M.; Petit, E.; Boulouis, H.J.; Moutailler, S.; Monroy, F.; Coello, M.A.; et al. Bovine anaplasmosis and tick-borne pathogens in cattle of the Galapagos Islands. Transbound Emerg Dis 2018, 65, 1262-1271. doi: 10.1111/tbed.12866.

21. Gondard, M.; Michelet, L.; Nisavanh, A.; Devillers, E.; Delannoy, S.; Fach, P.; Aspan, A.; Ullman, K.; Chirico, J.; Hoffmann, B.; et al. Prevalence of tick-borne viruses in Ixodes ricinus assessed by highthroughput real-time PCR. Pathog Dis 2018, 76. doi: 10.1093/femspd/fty083.

22. Malmsten, J.; Dalin, A.-M.; Moutailler, S.; Devillers, E.; Gondard, M.; Felton, A. Vector-Borne Zoonotic Pathogens in Eurasian Moose (Alces alces alces). Vector Borne Zoonotic Dis. 2018. doi: 10.1089/vbz.2018.2277.

23. Ahantarig, A.; Trinachartvanit, W.; Baimai, V.; Grubhoffer, L. Hard ticks and their bacterial endosymbionts (or would be pathogens). Folia Microbiol. (Praha) 2013, 58, 419-428. doi: 10.1007/s12223-013-0222-1.

24. Duron, O.; Binetruy, F.; Noël, V.; Cremaschi, J.; McCoy, K.D.; Arnathau, C.; Plantard, O.; Goolsby, J.; Pérez de León, A.A.; Heylen, D.J.A.; et al. Evolutionary changes in symbiont community structure in ticks. Mol. Ecol. 2017, 26, 2905-2921. doi: 10.1111/mec.14094.

25. Bonnet, S.; Jouglin, M.; Malandrin, L.; Becker, C.; Agoulon, A.; L'hostis, M.; Chauvin, A. Transstadial and transovarial persistence of Babesia divergens DNA in Ixodes ricinus ticks fed on infected blood in a new skinfeeding technique. Parasitology 2007, 134, 197-207. doi: 10.1017/S0031182006001545.

26. Yssouf, A.; Almeras, L.; Raoult, D.; Parola, P. Emerging tools for identification of arthropod vectors. Future Microbiol 2016, 11, 549-566. doi: 10.2217/fmb.16.5.

27. Diarra, A.Z.; Almeras, L.; Laroche, M.; Berenger, J.-M.; Koné, A.K.; Bocoum, Z.; Dabo, A.; Doumbo, O.; Raoult, D.; Parola, P. Molecular and MALDI-TOF identification of ticks and tick-associated bacteria in Mali. PLoS Negl Trop Dis. 2017, 11. doi: 10.1371/journal.pntd.0005762.

28. Howell, J.M.; Ueti, M.W.; Palmer, G.H.; Scoles, G.A.; Knowles, D.P. Transovarial Transmission Efficiency of Babesia bovis Tick Stages Acquired by Rhipicephalus (Boophilus) microplus during Acute Infection. J Clin Microbiol 2007, 45, 426-431. doi: 10.1128/JCM.01757-06.

29. Chauvin, A.; Moreau, E.; Bonnet, S.; Plantard, O.; Malandrin, L. Babesia and its hosts: adaptation to longlasting interactions as a way to achieve efficient transmission. Vet. Res. 2009, 40, 37 . doi: $10.1051 /$ vetres/2009020.

30. Robinson, J.B.; Eremeeva, M.E.; Olson, P.E.; Thornton, S.A.; Medina, M.J.; Sumner, J.W.; Daschi, G.A. New approaches to detection and identification of Rickettsia africae and Ehrlichia ruminantium in Amblyomma variegatum (Acari: Ixodidae) ticks from the Caribbean. J. Med. Entomol. 2009, 46, 942-951.

31. Socolovschi, C.; Huynh, T.P.; Davoust, B.; Gomez, J.; Raoult, D.; Parola, P. Transovarial and trans-stadial transmission of Rickettsiae africae in Amblyomma variegatum ticks. Clin. Microbiol. Infect. 2009, 15 Suppl 2, 317318. doi: 10.1111/j.1469-0691.2008.02278.x.

32. Maina, A.N.; Jiang, J.; Omulo, S.A.; Cutler, S.J.; Ade, F.; Ogola, E.; Feikin, D.R.; Njenga, M.K.; Cleaveland, S.; Mpoke, S.; et al. High Prevalence of Rickettsia africae Variants in Amblyomma variegatum Ticks from Domestic Mammals in Rural Western Kenya: Implications for Human Health. Vector Borne Zoonotic Dis 2014, 14, 693-702. doi: 10.1089/vbz.2014.1578. 
33. Yssouf, A.; Socolovschi, C.; Kernif, T.; Temmam, S.; Lagadec, E.; Tortosa, P.; Parola, P. First molecular detection of Rickettsia africae in ticks from the Union of the Comoros. Parasites \& Vectors 2014, 7, 444. doi: 10.1186/1756-3305-7-444.

34. Matsimbe, A.M.; Magaia, V.; Sanches, G.S.; Neves, L.; Noormahomed, E.; Antunes, S.; Domingos, A. Molecular detection of pathogens in ticks infesting cattle in Nampula province, Mozambique. Exp Appl Acarol 2017, 73, 91-102. doi: 10.1007/s10493-017-0155-5.

35. Rodriguez O.N.; Espaine, L.; Rivas, A.; Rodriguez, P.. Epidemiology of cattle diseases caused by haemoparasites in Cuba. Rev. Cuba. de Cienc. Vet. 1989, 20, 37-56.

36. Woolhouse, M.E.J.; Thumbi, S.M.; Jennings, A.; Chase-Topping, M.; Callaby, R.; Kiara, H.; Oosthuizen, M.C.; Mbole-Kariuki, M.N.; Conradie, I.; Handel, I.G.; et al. Co-infections determine patterns of mortality in a population exposed to parasite infection. Science Advances 2015, 1, e1400026. doi: 10.1126/sciadv.1400026.

37. Parola, P.; Inokuma, H.; Camicas, J.L.; Brouqui, P.; Raoult, D. Detection and identification of spotted fever group Rickettsiae and Ehrlichiae in African ticks. Emerg. Infect. Dis. 2001, 7, 1014-1017. doi: 10.3201/eid0706.010616.

38. Inokuma, H.; Beppu, T.; Okuda, M.; Shimada, Y.; Sakata, Y. Detection of ehrlichial DNA in Haemaphysalis ticks recovered from dogs in Japan that is closely related to a novel Ehrlichia sp. found in cattle ticks from Tibet, Thailand, and Africa. J. Clin. Microbiol. 2004, 42, 1353-1355.

39. Loftis, A.D.; Reeves, W.K.; Szumlas, D.E.; Abbassy, M.M.; Helmy, I.M.; Moriarity, J.R.; Dasch, G.A. Rickettsial agents in Egyptian ticks collected from domestic animals. Exp. Appl. Acarol. 2006, 40, 67-81. doi: 10.1007/s10493-006-9025-2.

40. Kang, Y.-J.; Diao, X.-N.; Zhao, G.-Y.; Chen, M.-H.; Xiong, Y.; Shi, M.; Fu, W.-M.; Guo, Y.-J.; Pan, B.; Chen, X.-P.; et al. Extensive diversity of Rickettsiales bacteria in two species of ticks from China and the evolution of the Rickettsiales. BMC Evol. Biol. 2014, 14, 167. doi: 10.1186/s12862-014-0167-2.

41. Lu, M.; Tian, J.-H.; Yu, B.; Guo, W.-P.; Holmes, E.C.; Zhang, Y.-Z. Extensive diversity of rickettsiales bacteria in ticks from Wuhan, China. Ticks Tick Borne Dis 2017, 8, 574-580. doi: 10.1016/j.ttbdis.2017.03.006.

42. Guo, W.-P.; Tian, J.-H.; Lin, X.-D.; Ni, X.-B.; Chen, X.-P.; Liao, Y.; Yang, S.-Y.; Dumler, J.S.; Holmes, E.C.; Zhang, Y.-Z. Extensive genetic diversity of Rickettsiales bacteria in multiple mosquito species. Sci Rep 2016, 6, 38770. doi: 10.1038/srep38770.

43. Yparraguirre, L.A.; Machado-Ferreira, E.; Ullmann, A.J.; Piesman, J.; Zeidner, N.S.; Soares, C.A.G. A hard tick relapsing fever group spirochete in a Brazilian Rhipicephalus (Boophilus) microplus. Vector Borne Zoonotic Dis. 2007, 7, 717-721. doi: 10.1089/vbz.2007.0144.

44. Hagen, R.M.; Frickmann, H.; Ehlers, J.; Krüger, A.; Margos, G.; Hizo-Teufel, C.; Fingerle, V.; Rakotozandrindrainy, R.; Kalckreuth, V. von; Im, J.; et al. Presence of Borrelia spp. DNA in ticks, but absence of Borrelia spp. and of Leptospira spp. DNA in blood of fever patients in Madagascar. Acta Trop. 2018, 177, 127-134. doi: 10.1016/j.actatropica.2017.10.002.

45. Kumsa, B.; Socolovschi, C.; Raoult, D.; Parola, P. New Borrelia species detected in ixodid ticks in Oromia, Ethiopia. Ticks Tick Borne Dis 2015, 6, 401-407. doi: 10.1016/j.ttbdis.2015.03.009.

46. Ehounoud, C.B.; Yao, K.P.; Dahmani, M.; Achi, Y.L.; Amanzougaghene, N.; Kacou N’Douba, A.; N'Guessan, J.D.; Raoult, D.; Fenollar, F.; Mediannikov, O. Multiple Pathogens Including Potential New Species in Tick Vectors in Côte d'Ivoire. PLoS Negl Trop Dis 2016, 10, e0004367. doi: 10.1371/journal.pntd.0004367.

47. Estrada-Peña, A.; Álvarez-Jarreta, J.; Cabezas-Cruz, A. Reservoir and vector evolutionary pressures shaped the adaptation of Borrelia. Infect., Genet. Evol. 2018, 66, 308-318. doi: 10.1016/j.meegid.2018.03.023.

48. Rodríguez, I.; Fernández, C.; Cinco, M.; Pedroso, R.; Fuentes, O. Do Antiborrelial Antibodies Suggest Lyme Disease in Cuba? Emerg Infect Dis 2004, 10, 1698-1700. doi: 10.3201/eid1009.031048.

49. Rodríguez, I.; Fernández, C.; Sánchez, L.; Martínez, B.; Siegrist, H.H.; Lienhard, R. Prevalence of antibodies to Borrelia burgdorferi sensu stricto in humans from a Cuban village. Braz J Infect Dis 2012, 16, 82-85. doi: http://dx.doi.org/10.1590/S1413-86702012000100015.

50. Dessau, R.B. Infection due to Borrelia burgdorferi most likely does not occur in Cuba. Braz J Infect Dis 2012, 16, 404; author reply 405-406. doi: 10.1016/j.bjid.2012.06.007.

51. Flanigan, T.P.; Schwan, T.G.; Armstrong, C.; Voris, V.; P, L.; Salata, R.A. Relapsing Fever in the US Virgin Islands: A Previously Unrecognized Focus of Infection. J Infect Dis 1991, 163, 1391-1392. doi: 10.1093/infdis/163.6.1391. 
52. Sharma, A.; Jaimungal, S.; Basdeo-Maharaj, K.; Rao, A.V.C.; Teelucksingh, S. Erythema Migrans-like Illness among Caribbean Islanders. Emerg Infect Dis 2010, 16, 1615-1617. doi: 10.3201/eid1610.100587.

53. Pothirat, T.; Tantiworawit, A.; Chaiwarith, R.; Jariyapan, N.; Wannasan, A.; Siriyasatien, P.; Supparatpinyo, K.; Bates, M.D.; Kwakye-Nuako, G.; Bates, P.A. First Isolation of Leishmania from Northern Thailand: Case Report, Identification as Leishmania martiniquensis and Phylogenetic Position within the Leishmania enriettii Complex. PLoS Negl Trop Dis 2014, 8, e3339. doi: 10.1371/journal.pntd.0003339.

54. Espinosa, O.A.; Serrano, M.G.; Camargo, E.P.; Teixeira, M.M.G.; Shaw, J.J. An appraisal of the taxonomy and nomenclature of trypanosomatids presently classified as Leishmania and Endotrypanum. Parasitology 2018, 145, 430-442. doi: 10.1017/S0031182016002092.

55. Leelayoova, S.; Siripattanapipong, S.; Manomat, J.; Piyaraj, P.; Tan-ariya, P.; Bualert, L.; Mungthin, M. Leishmaniasis in Thailand: A Review of Causative Agents and Situations. Am J Trop Med Hyg 2017, 96, 534542. doi: 10.4269/ajtmh.16-0604.

56. Steverding, D. The history of leishmaniasis. Parasit Vectors 2017, 10, 82. doi : 10.1186/s13071-017-2028-5.

57. Desbois, N.; Pratlong, F.; Quist, D.; Dedet, J.-P. Leishmania (Leishmania) martiniquensis n. sp. (Kinetoplastida: Trypanosomatidae), description of the parasite responsible for cutaneous leishmaniasis in Martinique Island (French West Indies). Parasite 2014, 21, 12. doi: 10.1051/parasite/2014011.

58. Liautaud, B.; Vignier, N.; Miossec, C.; Plumelle, Y.; Kone, M.; Delta, D.; Ravel, C.; Cabié, A.; Desbois, N. First case of visceral leishmaniasis caused by Leishmania martiniquensis. Am. J. Trop. Med. Hyg. 2015, 92, 317319. Doi: $10.4269 /$ ajtmh.14-0205.

59. Dantas-Torres, F. Ticks as vectors of Leishmania parasites. Trends Parasitol. 2011, 27, 155-159. doi: 10.1016/j.pt.2010.12.006.

60. Rakhshanpour, A.; Malmasi, A.; Mohebali, M.; Nabian, S.; Mirhendi, H.; Zarei, Z.; Dalimi, A.; Mohammadiha, A.; Akhoundi, B.; Azarm, A. Transmission of Leishmania infantum by Rhipicephalus sanguineus (Acari: Ixodidae) in Dogs. Iran J Parasitol 2017, 12, 482-489.

61. Rojas-Jaimes, J.E.; Correa-Nuñez, G.H.; Rojas, N.; Cáceres-Rey, O. Detection of Leishmania (V) guyanensis in Rhipicephalus (Boophilus) microplus (Acari: Ixodidae) collected from Pecari tajacu. Biomedica 2017, 37, $208-214$.

62. Alam, M.Z.; Rahman, M.M.; Akter, S.; Talukder, M.H.; Dey, A.R. An investigation about the possible role of cattle and goats as reservoir hosts for Leishmania donovani in Bangladesh. J Vector Borne Dis 2018, 55, 242 244. doi: 10.4103/0972-9062.249484.

63. Paixão-Marques, M.D.S.; Alves-Martin, M.F.; Guiraldi, L.M.; Dos Santos, W.J.; de Lemos, F.A.; Sánchez, G.P.; Richini-Pereira, V.B.; Lucheis, S.B. First isolation of Leishmania infantum by blood culture in bovines from endemic area for canine visceral leishmaniasis. Parasitology 2019, 1-3. doi: 10.1017/S0031182019000088.

64. Lamattina, D.; Nava, S. Ticks infesting humans in Northern Misiones, Argentina. Medicina (B Aires) 2016, 76, 89-92.

65. Walker, A.R.; Bouattour, A.; Camicas, J.-L.; Estrada-Pena, A.; Horak, I.G.; Latif, A.A.; Pegram, R.G.; Preston, P.M. Ticks of domestic animals in Africa: a guide to identification of species; illustrée.; Bioscience Reports: Wisconsin University- Madison, 2003; ISBN 0-9545173-0-X. Available online: https://pdfs.semanticscholar.org/cdda/35b475e0902e3db7559d5d155fa2b8afd42b.pdf?_ga=2.54794787.9215 40442.1582955237-1934342711.1568961768 (accessed on 12 February 2020)

66. Nielsen, E.M.; Andersen, M.T. Detection and Characterization of Verocytotoxin-Producing Escherichia coli by Automated 5' Nuclease PCR Assay. J Clin Microbiol 2003, 41, 2884-2893. doi: 10.1128/JCM.41.7.28842893.2003.

67. Regnery, R.L.; Spruill, C.L.; Plikaytis, B.D. Genotypic identification of rickettsiae and estimation of intraspecies sequence divergence for portions of two rickettsial genes. J. Bacteriol. 1991, 173, 1576-1589.

68. Choi, Y.-J.; Lee, S.-H.; Park, K.-H.; Koh, Y.-S.; Lee, K.-H.; Baik, H.-S.; Choi, M.-S.; Kim, I.-S.; Jang, W.-J. Evaluation of PCR-Based Assay for Diagnosis of Spotted Fever Group Rickettsiosis in Human Serum Samples. Clin Diagn Lab Immunol 2005, 12, 759-763. doi: 10.1128/CDLI.12.6.759-763.2005.

69. Hornok, S.; Földvári, G.; Elek, V.; Naranjo, V.; Farkas, R.; de la Fuente, J. Molecular identification of Anaplasma marginale and rickettsial endosymbionts in blood-sucking flies (Diptera: Tabanidae, Muscidae) and hard ticks (Acari: Ixodidae). Vet. Parasitol. 2008, 154, 354-359. doi: 10.1016/j.vetpar.2008.03.019.

70. Loh, S.-M.; Gofton, A.W.; Lo, N.; Gillett, A.; Ryan, U.M.; Irwin, P.J.; Oskam, C.L. Novel Borrelia species detected in echidna ticks, Bothriocroton concolor, in Australia. Parasit Vectors 2016, 9, 339. doi: 10.1186/s13071016-1627-x.

71. Albuquerque, A.; Campino, L.; Cardoso, L.; Cortes, S. Evaluation of four molecular methods to detect 
Leishmania infection in dogs. Parasit Vectors 2017, 10, 57. doi: 10.1186/s13071-017-2002-2.

72. Thompson, J.D.; Higgins, D.G.; Gibson, T.J. CLUSTAL W: improving the sensitivity of progressive multiple sequence alignment through sequence weighting, position-specific gap penalties and weight matrix choice. Nucleic Acids Res. 1994, 22, 4673-4680.

73. Tamura, K.; Nei, M. Estimation of the number of nucleotide substitutions in the control region of mitochondrial DNA in humans and chimpanzees. Mol. Biol. Evol. 1993, 10, 512-526. doi: 10.1093/oxfordjournals.molbev.a040023.

74. Kumar, S.; Stecher, G.; Tamura, K. MEGA7: Molecular Evolutionary Genetics Analysis Version 7.0 for Bigger Datasets. Mol. Biol. Evol. 2016, 33, 1870-1874. doi: 10.1093/molbev/msw054.

75. Mixson, T.R.; Campbell, S.R.; Gill, J.S.; Ginsberg, H.S.; Reichard, M.V.; Schulze, T.L.; Dasch, G.A. Prevalence of Ehrlichia, Borrelia, and Rickettsial Agents in Amblyomma americanum (Acari: Ixodidae) Collected from Nine States. J. Medical Entomol. 2006, 43, 1261-1268. doi: 10.1603/0022-2585(2006)43[1261:POEBAR]2.0.CO;2.

76. Trout Fryxell, R.T.; DeBruyn, J.M. The Microbiome of Ehrlichia-Infected and Uninfected Lone Star Ticks (Amblyomma americanum). PLoS One 2016, 11, e0146651, doi: 10.1371/journal.pone.0146651.

77. Aktas, M.; Özübek, S. Transstadial Transmission of Hepatozoon canis by Rhipicephalus sanguineus (Acari: Ixodidae) in Field Conditions. J. Med. Entomol. 2017, 54, 1044-1048. doi: 10.1093/jme/tjx050.

78. Hamšíková, Z.; Silaghi, C.; Rudolf, I.; Venclíková, K.; Mahríková, L.; Slovák, M.; Mendel, J.; Blažejová, H.; Berthová, L.; Kocianová, E.; et al. Molecular detection and phylogenetic analysis of Hepatozoon spp. in questing Ixodes ricinus ticks and rodents from Slovakia and Czech Republic. Parasitol Res. 2016, 115, 38973904. doi: 10.1007/s00436-016-5156-5.

79. Hailemariam, Z.; Krücken, J.; Baumann, M.; Ahmed, J.S.; Clausen, P.-H.; Nijhof, A.M. Molecular detection of tick-borne pathogens in cattle from Southwestern Ethiopia. PLoS One 2017, 12, e0188248. doi: 10.1371/journal.pone.0188248.

80. Laird, J.S.; Kocan, A.A.; Kocan, K.M.; Presley, S.M.; Hair, J.A. Susceptibility of Amblyomma americanum to natural and experimental infections with Theileria cervi. J. Wildl. Dis. 1988, 24, 679-683. doi: 10.7589/00903558-24.4.679.

81. Mans, B.J.; Pienaar, R.; Latif, A.A. A review of Theileria diagnostics and epidemiology. Int. J. Parasitol.: Parasites Wildl. 2015, 4, 104-118. doi: 10.1016/j.ijppaw.2014.12.006.

82. Njiiri, N.E.; Bronsvoort, B.M. deC; Collins, N.E.; Steyn, H.C.; Troskie, M.; Vorster, I.; Thumbi, S.M.; Sibeko, K.P.; Jennings, A.; van Wyk, I.C.; et al. The epidemiology of tick-borne haemoparasites as determined by the reverse line blot hybridization assay in an intensively studied cohort of calves in western Kenya. Vet. Parasitol. 2015, 210, 69-76. doi: 10.1016/j.vetpar.2015.02.020.

83. Oura, C. a. L.; Bishop, R.P.; Wampande, E.M.; Lubega, G.W.; Tait, A. Application of a reverse line blot assay to the study of haemoparasites in cattle in Uganda. Int. J. Parasitol. 2004, 34, 603-613. doi: 10.1016/j.ijpara.2003.12.012.

(C) 2020 by the authors. Licensee MDPI, Basel, Switzerland. This article is an open access article distributed under the terms and conditions of the Creative Commons Attribution (CC BY) license (http://creativecommons.org/licenses/by/4.0/). 